\title{
Oil Shocks and Macroeconomic Effects of Occasionally Binding Constraint on External Reserves of CEMAC
}

\author{
Thierry Mvondo \\ Department of Studies, Research and Statistics, Central African States Bank, Yaoundé, Cameroon
}

Email address:

mvondot@beac.int, thmvondo@gmail.com

\section{To cite this article:}

Thierry Mvondo. Oil Shocks and Macroeconomic Effects of Occasionally Binding Constraint on External Reserves of CEMAC. International Journal of Business and Economics Research. Vol. 8, No. 6, 2019, pp. 422-438. doi: 10.11648/j.ijber.20190806.23

Received: October 28, 2019; Accepted: November 22, 2019; Published: December 2, 2019

\begin{abstract}
This paper investigates the macroeconomic effects of Central African States Bank (BEAC) commitment to ensure its nominal anchoring when the underlying external reserves constraint occurs after an oil shock. Indeed, the current monetary agreements place external reserves at the heart of the cooperation between BEAC and the French Treasury, and their fluctuations are the main risks indicators to the durability of the cooperation between these two institutions: a system described as pegged to reserves which neither fully resembles a fixed exchange rate regime or a flexible exchange rate regime, much less an intermediate regime. To this end, there is a need to monitor their ability to cover a proportion of the central bank's liabilities in the short run by tithing the monetary conditions, in order to avoid drastic adjustment measures as devaluation. Therefore, as a result of the fall of these reserves below their long run threshold, the central bank essentially focused on their recovery. Our framework is a Markov-switching approach of the Smets and Wouters textbook model were we have modelled the dynamics of external reserves from the balance of payments identity and the simplified balance sheet of the central bank. The monetary policy rule is also augmented by the gap of reserves to their long run trend. Two scenarios are subsequently evaluated namely, a variation of the probability of occurrence of the constraint while maintaining that of leaving or, conversely, a variation of the probability of exit from the constraint by assuming that its occurrence is fixed. The results obtained show that at the approach of the constraint and in the presence of an oil shock, the behaviour of the central bank induces many undesired effects such as the fall in consumption, investment and production. Conversely, when the probability of exit from the constraint is high, the central bank adopts a somewhat passive behaviour, with a late reaction that makes the imbalances continue. Following the fact that (i) export revenue of the region are mainly composed of oil resources (84\%), (ii) imports are rigid and, (iii) the oil price cannot be under control of CEMAC countries for competitiveness purpose, the paper highlights the need for permanent monetary discipline alongside economic diversification.
\end{abstract}

Keywords: Occasionally Binding Constraint, External Reserves, Markov-Switching DSGE, Macroeconomics Effects

\section{Introduction}

The external reserves of the Economic and Monetary Community of Central Africa (CEMAC) decreased between 2014 and 2016, going from 4537.19 billion FCFA in December 2013 , to 2633.31 billion in June $2016^{1}$. This decline is a result of a slowdown in oil prices during this period, the pursuit of pro-cyclical fiscal policies and the irreversibility of the accompanying investments ${ }^{2}$.

1 BEAC, Rapport sur la politique monétaire 2016.

2 Final Communiqué of the Extraordinary Summit of Heads of State of Central Africa, December 2016.
According to the International Monetary Fund (IMF) ${ }^{3}$, the barrel of oil dropped by $65 \%$, falling from $\$ 110$ to $\$ 35$. This was because of: (i) the slowdown in the Chinese economy; (ii) the decline in global demand; (iii) the comeback of Iran in international trade and; (iv) the United States and Saudi Arabia rivalry for the control of the oil markets. In this context, the CEMAC states, whose investments were closely linked to oil revenues, (which account for $84 \%$ of the region's export earnings), had to face the challenge of continuing these investments, despite the oil prices shock and the impact of the importation of

3 World Economic Outlook, January 16, 2017. 
capital goods on external reserves. As a result, the external coverage rate of the currency fell from $80 \%$ to $50 \%$, the reserves in months of imports fell from 7 to 2.1 months, the inflation rate came back from $3.2 \%$ to $2.4 \%$ and the growth rate fell from $4.6 \%$ to $-0.1 \%$ according to the BEAC estimates.

In line with its objective ${ }^{4}$, the Bank of Central African States (BEAC) tightened its monetary conditions as of the first quarter of 2017, with the aim of reversing the downward trend of its foreign reserves. The measures adopted by BEAC consisted of a better application of foreign exchange regulations, and progressively raising of its policy rate from $2.45 \%$ to $3.50 \%$, with an intermediate value of $2.95 \%$. Within the same period, the CEMAC region also benefited from IMF funding from its member countries in program with the IMF and the states moderated their spending. As a result, foreign reserves began a new phase of growth to reach 3044.25 billion FCFA in September 2017 from 2633.31 billion in June of the same year. Reserves in months of imports returned to the 3-month threshold by the end of 2017. According to a study [1] carried out by BEAC for the period of January to September 2017, although the average monthly growth rate of BEAC's foreign exchange reserves was negative $(-0.14 \%)$, the contributions of IMF loans and a more rigorous implementation of the regulation on foreign transfers to this average were positive, $2.55 \%$ and $0.91 \%$ respectively. Moreover, the restrictive monetary policy implemented by restraining the growth of domestic credit below monetary growth, contributed positively to the positive dynamics of the zone's foreign exchange reserves.

However, following [2], an attempt to stabilise the external coverage rate of the currency, through the impact of the interest rate on the monetary base could induce undesired effects on inflation. Such an evolution would then lead, in an initial context of price stability, to pessimistic expectations from producers and ultimately to an accentuation of the downward trend in production. Concretely, the monetary destruction mechanism underlying a restrictive monetary policy will induce, depending on the origin of inflation, a process of disinflation or deflation. Because of the ripple effect, producers who anticipate a fall in yields due to the reduction of the gap between prices and marginal costs will reduce their level of investment and ultimately there will be a drop in production. In this regard, Annex Appendix 1 gives an idea of the correlations between oil price, external reserves, policy rate, external coverage rate of the currency, inflation rate and GDP growth of CEMAC region. This appendix shows above all that, beyond the reversal of the downward trend in reserves, as seen above, the macroeconomic effects of this stabilization acquired at the cost of giving less importance to the internal counterpart of the monetary policy objective of BEAC are to be investigated. More specifically, this paper focus on the scope

4 According to its Statutes, this objective is monetary stability which means, internally, a low rate of inflation (the sub-regional standard being 3\%) and, externally, an adequate external coverage rate of the currency (compatible with three months of imports of goods and services and short-term debt service). of the underlying monetary policy rule. Following [3], it is a Taylor type rule augmented by the gap of foreign reserves to their long run trend, with at least two regimes: depending on whether or not the external reserves constraint occurs.

The unanimous approach to address the above question after the critique illustrated in [4] is the Dynamic and Stochastic General Equilibrium (DSGE) model. This model assumes that economic agents are optimizers and rational, and, following the impulse/propagation principle, allows the analysis of temporally shift to long run equilibrium. Some later developments, summarized in [5], introduce constraints on variables and regime switching. Thus, it is assumes that the constraint is binding every time [6]. This is the case of models for evaluating the financial accelerator [7-11] and collateral constraint [12-14]. However, the Blanchard and Khan [15] condition will felt with a non-negative policy rate constraint.

To overcome this pitfall, the method of smooth approximation has been proposed as seen with [5, 16, 17]. The nonlinear resolution techniques it uses assume that agents can violate the constraint at a cost. At the same time, another approach has been to impose additional shocks to constraint collateral borrowing, as well as the non-negativity of the policy rate [18]. Instead of additional shocks, [19] suggest the anticipated nature of them. The limit of this approach according to [4] is the reversibility of the signs and the trap of the forward guidance 5 . Ultimately, whatever the approach adopted, there is a problem of certain equivalence 6 which induces the superiority of methods based on regime switching [20-23].

In order to examine the effects of BEAC's dual behaviour around its external reserves constraint, we adapt the model proposed by [24] to our problem. Thus, the number of rigidities and shocks implemented is reduce and we modelled the dynamics of external reserves from the balance of payments account and central banks simplified balance sheet. We captured its impact on the key interest rate by introducing its deviation from its long run trend into the dynamics of interest rate. We also impose a constraint on the nonnegativity of the gap between external reserves and their long run trend. Therefore, we have evaluated two scenarios namely, a variation of the probability of occurrence of the constraint while maintaining fixed that of exit or contrary, a variation of the probability of exit from the constraint while supposing fixed the probability of its occurrence. The results obtained show that as we approach the constraint and especially with the presence of an oil shock which results in a depletion of foreign reserves, the behaviour of the central bank induces numerous unwanted effects such as the fall in consumption, investment and production.

Specifically, following the fall in inflation, consumption and production, and a rise in the external coverage rate, the model advocates a tightening of monetary conditions in response to the decline in external reserves. This fear of the

\footnotetext{
5 In this context, agents are aware of shocks only at their occurrence. 6 The constraint affects agent behaviour without concern of its occurrence.
} 
occurrence of the constraint persist with low probabilities, low impact on consumption, deceleration of inflationary pressures, fall in activity and, significant rise of external reserves coverage ratio. It also persists when the probability of recovery from the oil shock is low, or where the central bank reacts instantly, thereby avoiding some adverse effects. On the other hand, when the probability of non-occurrence of the constraint is high, the central bank adopts a passive behaviour, with a late reaction. This explains the appearance of imbalances several periods after the occurrence of the shock. Point (4) present these simulations, point (1) dwells on the importance of external reserves in the cooperation framework with the French Treasury, point (2) introduces the constraint of reserves in the model proposed by [24] and point (3) presents the other model relationships.

\section{The Importance of External Reserves in the Cooperation Framework with the French Treasury}

In a fixed exchange regime, the price of a currency is set against a reference currency or basket of currencies. The central bank then engages in a process of purchase/sale of the national currency, to minimize the fluctuations of this price depending on the evolution of supply and demand of the said currency. This practice, which aimed at ensuring the price competitiveness of a country or a currency area, does not apply to the CEMAC region [25]. Indeed, the current monetary agreements place external reserves at the heart of the cooperation between BEAC and the French Treasury, and their fluctuations are the main risks indicators to the durability of the cooperation between these two institutions [26]. To this end, there is a need to monitor their ability to cover a proportion of the central bank's liabilities in the short run, in order to avoid drastic ${ }^{7}$ adjustment measures. In this regard, article 11.2 of BEAC's articles of association proscribes an external reserves coverage rate of less than $20 \%$ over three consecutive months, otherwise they would have to face a reduction in the maximum refinancing amounts per State.

This article also states the procedure to follow when a member State has a deficit in the Operations Account. In return, the principles of the monetary cooperation agreement of 23 November 1972 in Brazzaville between France and the BEAC member states specify the advantages that the central bank can claim. These are: (i) the guarantee of unlimited convertibility of the CFA franc by the French treasury; (ii) the fix parity, ensuring that the currency is convertible, at fixed parities, with no limit of amount, with those issued by the other central banks of the Franc Zone; (iii) free transferability within the Franc Zone. However, BEAC centralize the foreign reserves of the Member States and then transfers them to the operations account held by the French

7 Mid 1980's economic crisis implications, CFA devaluation and adjustment measures due to oil shock are some examples.
Treasury.

Such a system, often described as pegged to reserves, neither fully resembles a fixed exchange rate regime or a flexible exchange rate regime, much less an intermediate regime, could leave no one indifferent as to its advantages or disadvantages and more specifically to the role assigned to foreign reserves. On one hand, the abandonment of the management of the external value of the CFA franc to the pegged currency is pointed out [25] and, on the other hand, attention was focused on the optimal level of accumulation of external reserves in relation to financing of economies [27]. On the first point, it is not fortuitous to recall that a central bank can let its currency depreciate well below the target price ${ }^{8}$, to strengthen its price competitiveness. As a result, there is a gain of external reserves and thus a greater confidence in its currency. In the opposite case of a voluntary appreciation of its currency and in relation to the evolution of the real effective exchange rate, we talk of a "tax" on exports and a "subsidy" on imports. This scheme depends on exchange-rate sensitivity of export and import structure according to the Marshall-Lerner condition; a non-valid in CEMAC region in which export revenue are mainly composed of oil resources $(84 \%)$ and imports are rigid $^{9}$.

In relation to the second point, the rate of the external currency covering, which is sometimes compatible with the principles of currency boards, may be misleading. However, we must also take into consideration the characteristics of agents and financial markets that do not favour a maturity transformation and a risk division [28], as well as the very high exposure of the economies of the sub-region to exogenous shocks [29]. In this regard, a recurring question is why the accumulation of external reserves does not give way to a sufficient monetary creation for financing CEMAC economies. To understand this question, we must start from the monetary approach of the balance of payments, the basis of BEAC's monetary policy. It is an analytical framework designed for small open economies used by international institutions in the design of structural adjustment programs and more specifically in the balancing of their balance of payments accounts. Its major advantage is that it leads to the derivation of a credit volume compatible with the objective of external reserves coverage (three months of imports of goods and services for example). The analysis take in account five assumptions, namely: (i) the absence of a capital market; (ii) the exchange rate fixity and price rigidity; (iii) the exogeneity of exports and domestic credit; (iv) the lack of correlation between money demand and the interest rate and; (v) a constant velocity of money. Following this approach, the origin of the balance of payments imbalances is a consequence of higher growth in credit than that of the money supply. On a purely theoretical level, we can question

8 IMF recommend $2 \%$ for a fix exchange regime.

9 According to the UNCTAD Handbook of Statistics (2008), the CEMAC countries imported 50 per cent of the 260 products. 
the neoclassical framework that underlies it, in particular the quantity theory of money. It is a short-term adjustment framework where prices are rigid and interest rates nonsignificant.

The reform of BEAC's monetary policy have abandoned it for the new neoclassical synthesis and, the steering of the monetary base gave way to the steering of interest rates [2]. Empirically, despite the margin sometimes found between the targeted foreign reserves level and the actual level, it is important to note that the process of transforming maturities and dividing the underlying risk is the role of commercial banks and not that of the central bank. The central bank only ensures the refinancing of a proportion of the credits granted by the former. This process depends on the collateral presented by the commercial banks. In fact, these banks face high risks, given to the quality of the firms that operates in the economy: small and medium-sized companies with poor balance sheets over three consecutive years and a low probability of survival [30]. Because of the underlying risk premium, the gap between the central bank's interest rate and the interest rates offered by the commercial banks is significant.

Another factor likely to justify the high levels of reserves accumulation observed is the need to smooth the exogenous shocks faced by the economies of the area through the common pool of reserves. Indeed, for economies that depend mainly on oil [31] and which, moreover cannot influence barrel prices, an oil price shock effects felt very quickly in terms of external reserves stock erosion. Here we can mention the oil counter-shocks of the 1973-1974 and 1977-1978 periods or the oil shock of 2014-2016. To cope with this and given the degree of asymmetry of the shocks [32-34] in the CEMAC region, a centralization principle [34] is the practice and constitutes a guarantee presented by BEAC in order to benefit of the anchoring to the Euro. This is the main importance of these reserves according to [35], alongside the deterrence against speculative attacks.

IMF reiterated these two reasons in its guidelines for the management of external reserves. Their accumulation is justify by the need to create and maintain confidence in monetary and exchange rate management policies. This includes also the ability to intervene to support the national or common currency. A second argument is the necessity to limit external vulnerability by maintaining liquid exchange reserves in order to absorb shocks in times of crisis or, when access to credit is restricted. In doing so, this give markets assurance that the country is able to fulfil its external obligations. It also demonstrate that external assets support the national currency. However, such an accumulation can lead to internal and external consequences when it proves excessive. Internally, it can induce financial imbalances, themselves resulting from incomplete or ineffective sterilization operations [36]. Externally, an excessive accumulation of reserves can exacerbate commercial competition and increase tensions between the countries of the union.

\section{Specification of the Reserves Constraint in the Smets and Wouters Textbook Model}

For a better introduction of the constraint on external reserves, it is necessary to start from BEAC's objective and framework for monetary policy elaboration. Thus, the objective assigned to it is monetary stability: a sufficient external coverage rate of the currency ${ }^{10}$ and a low level of inflation ${ }^{11}$. According to article 7 of its articles of association, BEAC reserves the right, when there is no threat to these two components of its objective, to assist the economies of the CEMAC zone. Of all the above, we find on the one hand the two arguments of Taylor's rule namely inflation and activity and, on the other hand, the dynamics of an indicator of external reserves. Thus, assuming the use of the rule above, there is a need to augment it in other to capture BEAC's behaviour. In practice, a policy rate consistent with the three dimensions of the above objective is determined on BEAC's decision-making horizon (the three months separating two Monetary Policy Committees), with a review of its consequences on the horizon of the effects of this policy, i.e. about two years.

The underlying rate management framework then requires that BEAC, beyond its standard weekly operations, intervene in the money market to maintain interbank rates around its policy rate, within a corridor dictated by the interest rates of its permanent lending facilities and that of its deposit facilities, also known as the interest rate corridor. Of all the above, three observations can be made. The first is of an empirical nature, the second relates to the nature of the constraint that result from it and the third to the definition of this corridor. Observation of the facts show that when the external reserves of BEAC fall below a threshold that can be qualified as medium or long term, this institution concentrates a large part of its efforts on the stabilization of this indicator. Which is also part of the principles ${ }^{12}$ and particularities ${ }^{13}$ of anchorage to the Euro. The situation that preceded the 1994 devaluation and the recent downturn in oil prices are examples of this. As a result, the level of external reserves deviating from this threshold thus appears as a decision variable. Therefore, in addition to this constraint, to the behaviour of the central bank must be associated, the Kuhn and Tucker and complementary slackness conditions.

\footnotetext{
10 The sub-regional target is three months of imports of goods and services and short-term debt service.

11 The sub-regional convergence criterion is used here, namely an annual average inflation rate of less than or equal to $3 \%$.

12 The principles of the monetary union, four in number, was adopted in the monetary cooperation convention of 23 November 1972 in Brazzaville between France and the member states of the BEAC issuing area. These are: (i) the guarantee of unlimited convertibility of its currency in relation to the Euro; (ii) the fixity of the parity; (iii) free transferability; and (iv) the centralization of foreign exchange reserves at BEAC on the one hand and the Operations Account (50\%) on the other hand. These features relate to the Operating Account Agreement and the cooperation with France.

13 These features relate to the Operating Account Agreement and the cooperation with France.
} 
In relation to the specification of this constraint, it is necessary to start from its connection with the decision rule of BEAC. Indeed, the variable likely to establish this link is the external coverage ratio of the currency, which has the advantage of representing the external counterpart of the central bank's monetary policy objective. On the one hand, there is a negative correlation of the dynamics of this ratio with the policy rate and, on the other hand, its mathematical expression makes it possible to highlight the variable to which the constraint relates. Thus, the improvement of this coverage ratio in relation to its long run trend reflects the improvement in the external conditions of the currency and vice versa. Likewise, this ratio is between external reserves and BEAC commitments. However, since the central bank's simplified balance sheet has external reserves on assets and the institution's liabilities as counterpart, this ratio could have remained unchanged under certain assumptions ${ }^{14}$ since the exit or entry of external reserves resulted in an equivalent decrease or an increase of the monetary base. Following the automatic balance sheet adjustment view above, an external coverage rate of the currency would be compatible with several levels of external reserves and therefore liabilities: which is not acceptable in relation to accuracy of the compatibility of this rate with three months of imports of goods and services, including short-term debt service. Therefore, when the level of external reserves falls below the threshold of three months of imports of goods and services and debt service, BEAC triggers measures to reconstitute them through quantitative and qualitative actions on its commitments. One could mention here mainly the rise of the policy rate to ensure the constraint on demand for money.

To obtain an algebraic expression of the behaviour of BEAC and the related constraints, we admit that:

The central bank sets its policy rate according to a Taylor type rule augmented by the reserves gap to their long run trend, either

$$
T I A O=\rho T_{I A O}+1+(1-\rho) f\left[\left(\pi_{t}-\bar{\pi}\right) ; \hat{x}_{t} ;\left(A E x_{t}-\overline{A E x}_{t}\right)\right]
$$

TIAO is the policy rate, $\left(\pi_{t}-\bar{\pi}\right)$ the inflation differential at its target, $\hat{x}_{t}$ the output gap and $\left(A E x_{t}-\overline{A E x}_{t}\right)$ the reserves gap to their long run trend;

The economy is characterized by low elasticities of its foreign trade with the exception of oil, whose price dynamics (PP) influences that of external reserves (AEx) alongside capital movements, which allows us to write $x_{t}=$ $g\left(P P_{t-i} ; M K\right)$;

Households derive utility from the holding of cash, which allows for a first closure of the system assuming that this cash is, according to the multiplier principle, linked to the monetary base which itself responds to the policy rate;

The central bank's simplified monetary situation is the

14 It is mainly assumed that after a period of analysis (the quarter in our case), there are no leaks or unjustified ticket and coin entries. Otherwise, it could be money laundering or even currency acquisition by non-system resources. Similarly, one is led to believe that the adjustments between the assets and the liabilities of the simplified balance sheet do not take much time so as to be beyond the period of analysis. second closure relationship. It expresses external assets as the difference between the monetary base (MB) and the liabilities, and then the domestic assets of the central bank (AI) is:

$$
A E x_{t}=B M L-A I_{t}+E N G_{t} \text {. }
$$

In this expression, (BM) is the monetary base and (AI) domestic assets such as claims on the state and commercial banks. This relationship shows that any expansive credit policy reduces external reserves, especially when money creation results in imports ${ }^{15}$.

Thus, $A E x_{t}$ be the current level of external reserves, $\overline{A E x_{t}}$ their trend level, the constraint is

$A E x_{t} \geq \overline{A E x_{t}}$. The Kuhn and Tucker conditions and additional relaxation that result are:

$$
\begin{gathered}
\lambda_{t}\left(A E x_{t}-\overline{A E x_{t}}\right)=0 \\
\text { with } \\
A E x_{t}>\overline{A E x_{t}}, \lambda_{t}=0 \text { ou } A E x_{t}=\overline{A E x_{t}}, \lambda \prec 0
\end{gathered}
$$

Subsequently, we will consider the trend assets as an unobservable variable extracted by a filtering technique. The switching regime specification therefore leads us to introduce a two-state Markov chain: the realization of the constraint (B) and its non-realization $(\mathrm{N})$. The switching regime parameter $\phi\left(s_{t}\right)$ takes the values:

$$
\phi(N)=0 \quad \text { and } \quad \phi(B)=1
$$

The complementary relaxation condition become:

$$
\phi\left(s_{t}\right)\left(A E x_{t}-\overline{A E x_{t}}\right)+\left(1-\phi\left(s_{t}\right)\right) \lambda_{t}=0
$$

The evolution of the underlying Markov chain follow the transition matrix given by:

$$
Q_{t, t+1}=\left[\begin{array}{cc}
1-p_{N B, t} & p_{N B, t} \\
p_{B N, t} & 1-p_{B N, t}
\end{array}\right]
$$

Where $p_{N B, t}$ is the transition probability from state $\mathrm{N}$ to state $\mathrm{B}$ or inversely.

\section{Agents of the Model and Their Programs}

We use a simplified version of the model in [24], which has become the reference framework for monetary policy simulations. Simplification focuses on the nature of the rigidities and shocks that affect the system. Thus, we introduce four types of rigidities, namely: consumption habits, adjustment costs on investment, price and wage rigidities. Compared to the original model, we consider only five shocks instead of ten. These are preferences, productivity, monetary and cost shocks (labour markets and intermediate goods). To these five shocks, we add the shock on the dynamics of oil prices, which drives external reserves.

15 This is particularly the case when the monetary base and thus the demand for money grows less than the monetary creation. 
The model has three types of agents namely households, firms (intermediate and final good) and the central bank. The agent programs and the leading conditions that flow from them are below.

\subsection{Households}

We assume a continuum [0, 1] of indexed households (j) whose utility function has three arguments: consumption $\left(\mathrm{C}_{\mathrm{j}}\right.$, $\mathrm{t}$ ), labour $\left(\mathrm{L}_{\mathrm{j}, \mathrm{t}}\right)$ and real cash $\left(\mathrm{M}_{\mathrm{j}, \mathrm{t}} / \mathrm{Pt}\right)$. The objective of each household is to maximize its expected utility, provided below, under a budget constraint:

$$
\operatorname{Max} E\left[\sum_{t=0}^{\infty} \beta^{t} U_{j}\left(C_{j, t}, L_{j, t}, \frac{M_{j, t}}{P_{j, t}}\right)\right]
$$

The associated constraint equates its total wealth (real cash, assets and income) with its consumption, capital investment and new portfolio:

$$
\frac{M_{j, t-1}}{P_{t-1}}+\frac{B_{j, t-1}}{P_{t-1}}+Y_{j, t}=C_{j, t}+\frac{M_{j, t}}{P_{t}}+\frac{B_{j, t}}{P_{t}}+I_{j, t}
$$

Instant utility and income are:

$$
\begin{gathered}
U_{j}=\left[\frac{\left(c_{j, t}-h C_{j, t-1}\right)^{1-\sigma_{C}}}{1-\sigma_{C}}-\frac{L_{j, t}^{1+\sigma_{L}}}{1+\sigma_{L}}+\frac{\frac{M_{j, t}^{1-\sigma_{M}}}{P_{t}}}{1-\sigma_{M}}\right] \varepsilon_{t}^{C} \\
Y_{j, t}=W_{j, t} L_{j, t}+\left[R_{t}^{K}-v\left(U_{t}^{K}\right)\right] K_{j, t-1}+\frac{\Pi_{j, t}}{P_{t}}
\end{gathered}
$$

In relation (3), the parameters $\sigma_{C}, \sigma_{L}$ et $\sigma_{M}$ are respectively the inverse of the intertemporal elasticity of consumption, the inverse of the elasticity of substitution of labour to real wages and the inverse of the intertemporal elasticity of substitution of money. Relation (4), on the other hand, shows that household income depend on three elements: real wages, net interest on the service of capital and profits distributed to it by intermediate firms. The resolution of the household program provides the following first order conditions with respect to consumption and real money holding:

$$
\begin{aligned}
& \beta E\left[\frac{\left(C_{j, t+1}-h C_{j, t}\right)^{-\sigma_{C}}}{\left(C_{j, t}-h C_{j, t-1}\right)^{-\sigma_{C}}} \frac{R_{t} P_{t}}{P_{t-1}}\right]=1 \\
& \frac{M_{j, t}}{P_{t}}=\left(C_{j, t}-h C_{j, t-1}\right)^{-\sigma_{C}}+\frac{1}{R_{t}}
\end{aligned}
$$

In relation to wages, these are set in order to optimize the objective-function of households under two constraints, the budget constraint and the labour demand such as:

$$
L_{j, t}=L_{t}\left(\frac{\widetilde{W}_{j, t}}{\widetilde{W}_{t}}\right)^{\frac{-\left(1+\lambda_{t}^{W}\right)}{\lambda_{t}^{W}}}
$$

In this relationship, $\mathrm{L}_{\mathrm{t}}$ is the aggregate labour demand, $\widetilde{W}_{t}$ the aggregate nominal wage rate and $\lambda_{t}^{W}$ the price elasticity of demand for the input (j) or the mark-up rate for the labour supply type (j). Its dynamic is such that $\lambda_{t}^{W}=\lambda^{W}+\eta_{t}^{W}$.
Labour demand and the aggregate wage rate are:

$$
\begin{aligned}
& L_{t}=\left[\int_{0}^{1} \frac{1}{L_{j, t}^{\left(1+\lambda_{t}^{W}\right)}} d j\right]^{1+\lambda_{t}^{W}} \\
& \bar{W}_{t}=\left[\int_{0}^{1} \bar{W}_{j, t}^{-\frac{1}{\left(1+\lambda_{t}^{W}\right)}} d j\right]^{-\lambda_{t}^{W}}
\end{aligned}
$$

Assuming a wage dynamics with partial indexation and Calvo type rigidities [37], the probability of seeing a household (j) change its wage level is $1-\xi^{W}$.

For this purpose, the optimal level of salary is $W_{j, t}^{*}$. It is the one that equalizes the updated marginal return of labour at the discounted marginal cost of labour plus the mark-up. We write:

$$
\left.\frac{W_{j, t}^{*}}{P_{t}} E\left[\sum_{s=0}^{\infty} \beta_{E\left[\left(\xi_{W}\right)^{s} L_{i, t+s} U_{L, t+s}^{\prime}\right]} \beta_{W}\right)^{s} \frac{\left(\frac{P_{t}}{P_{t-1}}\right)^{\gamma^{W}}}{\frac{P_{t+s}}{P_{t+s-1}}} \frac{U_{C, t+s}^{\prime}}{1+\lambda_{t+s}^{W}}\right]=
$$

Households that do not optimize their nominal wage level index it at prices according to a parameter $\gamma^{W}$ such as:

$$
\bar{W}_{j, t}=\left(\frac{P_{t-1}}{P_{t-2}}\right)^{\gamma^{W}} \bar{W}_{j, t}
$$

The aggregate level of the nominal wage is therefore:

$$
W_{t}^{-\frac{1}{\lambda_{t}^{W}}}=\xi^{W}\left(\frac{P_{t-1}}{P_{t-2}}\right)^{\gamma^{W}} W_{j, t}+\left(1-\xi^{W}\right)\left(W_{j, t}^{*}\right)^{-\frac{1}{\lambda_{t}^{W}}}
$$

Households invest under the following capital accumulation constraint:

$$
\int_{0}^{1} K_{t}=(1-\delta) \int_{0}^{1} K_{t-1}+\int_{0}^{1}\left[I_{j, t}-S\left(\frac{I_{j, t}}{I_{j, t-1}}\right)\right]
$$

In this expression, (S) is a function of the investment adjustment costs faced by households. From the relation (13), the first order conditions are:

$$
\begin{gathered}
Q_{t}=E\left\{\beta \frac{U_{C, t-1}^{\prime}}{U_{C, t}^{\prime}}\left[Q_{t+1}(1-\delta)+U_{t+1}^{K} R_{t+1}^{K}\right]\right\} \\
1=Q_{t} S^{\prime}\left(\frac{I_{j, t}}{I_{j, t-1}}\right) \frac{I_{j, t}}{I_{j, t-1}}-\beta\left[\frac{U_{C, t-1}^{\prime}}{U_{C, t}^{\prime}}\left(\frac{I_{j, t+1}}{I_{j, t}}\right)^{2}\right] \\
R_{t}^{K}=v^{\prime}\left(U_{t}^{K}\right)
\end{gathered}
$$

\subsection{The Firm Producing the Final Good}

This firm evolves in an environment characterised by pure and perfect competition. It produces consumption goods $\left(\mathrm{Y}_{\mathrm{t}}\right)$ 
by combining ( $\mathrm{n}$ ) intermediate goods according to a Dixit and Stiglitz technology [38] such as:

$$
Y_{t}=\left[\int_{0}^{1} y_{i, t}^{\frac{1}{1+\lambda_{t}^{p}}} d i\right]^{1+\lambda_{t}^{p}}
$$

In this relation, $\lambda_{t}^{P}$ is the elasticity of substitution of good (i) and one has $\lambda_{t}^{P}=\lambda^{P}+\eta_{t}^{P}$. By minimizing the production costs of this firm, the demand for an intermediate good (i) and the price index are:

$$
\begin{gathered}
y_{i, t}=Y_{t}\left(\frac{p_{i, t}}{P_{t}}\right)^{-\frac{\left(1+\lambda_{t}^{P}\right)}{\lambda_{t}^{P}}} \\
P_{t}=\left[\int_{0}^{1} p_{i, t}^{-\frac{1}{\lambda_{t}^{P}}} d i\right]^{-\lambda_{t}^{P}}
\end{gathered}
$$

In relation (19), $\mathrm{p}_{\mathrm{i}, \mathrm{t}}$ is the index of an intermediate price.

\subsection{The Firm Producing the Intermediate Goods}

The intermediate goods firm uses a Cobb-Douglas technology to produce the intermediate good $y_{i}, t$. This technology is:

$$
y_{i, t}=\varepsilon_{t}^{a} U_{t}^{K} K_{i, t}^{\alpha} L_{i, t}^{1-\alpha}
$$

She face a shock $\varepsilon_{t}^{a}$ following an autoregressive process given by $\varepsilon_{t}^{a}=\rho^{a} \varepsilon_{t-1}^{a}+\eta_{t}^{a}$. The minimization of the costs of this firm under the constraint of its production function provided:

$$
\begin{gathered}
\frac{\bar{W}_{t} L_{i, t}}{R_{t}^{K} U_{t}^{K} K_{i, t}}=\frac{1-\alpha}{\alpha} \\
C M=\frac{1}{\varepsilon_{t}^{a}} \bar{W}_{t}^{1-\alpha}\left(R_{t}^{K}\right)^{\alpha}\left(\alpha^{-\alpha}(1-\alpha)^{\alpha-1}\right)
\end{gathered}
$$

Of all the above, the nominal profit is:

$$
\Pi_{i, t}=Y_{t}\left(\frac{p_{i, t}}{P_{t}}\right)^{-\frac{\left(1+\lambda_{t}^{P}\right)}{\lambda_{t}^{P}}}\left(p_{i, t}-C M_{t}\right)
$$

Considering the monopoly power available to the intermediate firm, its price-fixing procedure, like wages, includes imperfect indexing and nominal rigidity of the type propose in [37]. As a result, firms that are likely to change their prices do so according to a probability and the firstorder condition that results from their program is:

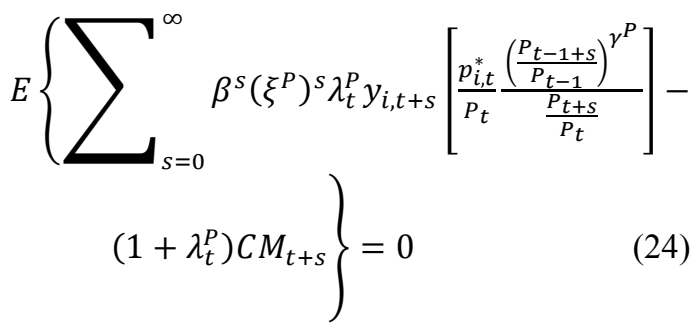

The resulting aggregate price level is therefore:

$$
P_{t}^{-\frac{1}{\lambda_{t}^{P}}}=\left(\xi^{P}\right)^{s}\left[P_{t-1}\left(\frac{P_{t-1}}{P_{t-2}}\right) \gamma^{P}\right]^{-\frac{1}{\lambda_{t}^{P}}}+\left(1-\xi^{P}\right)\left(p_{i, t}^{*}\right)^{-\frac{1}{\lambda_{t}^{P}}}
$$

The model is log-linearized around the steady state and these relations appears in Appendix 2.

\section{Calibration and Simulations}

\subsection{Obtaining the Model Parameters}

The structural parameters come from related studies while the parameters of the autoregressive processes and shocks were set for the simulation needs at 0.7 and 1 respectively. The values of the semi-elasticity of the interest rate on the money demand $\left(\sigma_{C}=0,4\right)$ and that of the multiplier (xteur $=$ 2.01) were obtained by closing the calibration, to ensure the overall consistency of the latter. The values obtained proved to be close to the empirical evidence in the area. This is verify with [39] on the money demand on the one hand, and with [40] on the multiplier on the other hand, were it appear that the money demand is very insensitive to the interest rate and the multiplier value is between one and two. The values of the variables in the steady state appears as averages over the period 2012-2015. In all that follows, we focus on obtaining the structural parameters.

The parameter of external consumption habits $(\mathrm{h}=0.86)$ and that of the inverse of the elasticity of substitution of consumption $\left(\sigma_{C}=5,62\right)$ result from the work in [41]. The discount parameter (beta $=0.91$ ) derives from the work in [42], assuming a lending rate of $10 \%$. In relation with the parameters of the monetary policy rules, we use the results on the area [43 and 44] that show that the smoothing coefficient would be between 0.85 and 0.98 . To confer significant regulatory power in the presence of a negative oil shock, we set it at 0.9 . In the same vein, the weight given to inflation in the Taylor type rule augmented by the gap of external reserves to its long run trend is less than that often encountered in literature (1.5). This is because the monetary authority is less interested in inflation when external equilibrium is threatened. The reconstitution of reserves is thus Primacy. We then haves

$$
\rho_{R}=0,9, \rho_{\pi}=1,2, \rho_{Y}=0,5 \operatorname{and} \rho_{A E X}=1,5
$$

The wage and price indexation parameters, as well as the probabilities of changing these, result from [2]. The value of the depreciation rate (delta $=0.025)$ is similar to that found in literature related to developing countries. The parameter relating to the contribution of oil revenues in the dynamics of the current account $\left(a_{1}=0.8\right)$ was fixed on the assumption that the balance of the latter is more influenced by oil revenues, the other items being assumed to be stable. Parameters $a_{2}, b_{1}$ and $c_{1}$ are coefficients of the autoregressive process of oil price, capital account and domestic assets respectively. The table in Appendix 3 summarise the calibrated values of the model.

\subsection{Likelihood of the Model in a One-regime Environment}

In the simulations below, we evaluate the ability of the 
model in a linear environment to replicate the stylized facts expected from the major shocks. We are talking here about an oil shock (negative, a monetary policy shock (tightening of monetary conditions), inflationary shock and a productivity shock. The reactions to other shocks are in Appendix 4.
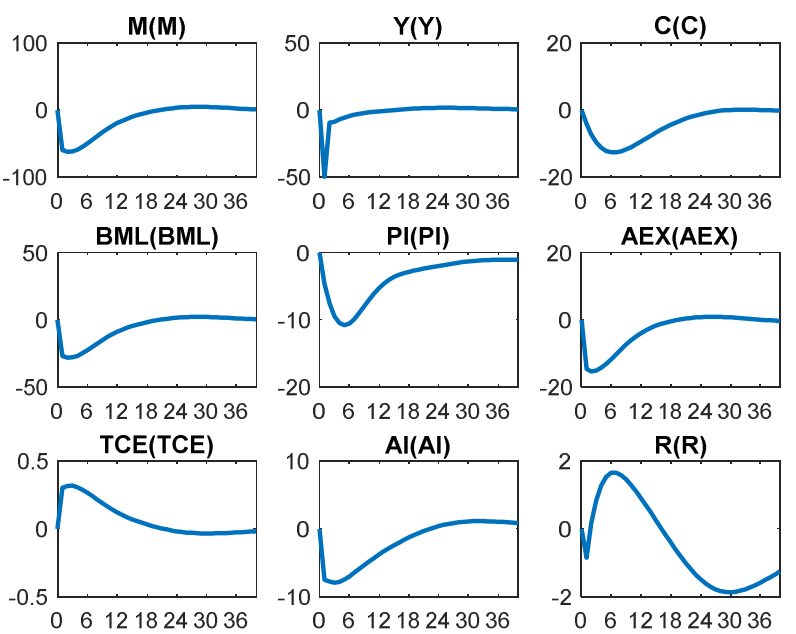

(Oil shock).
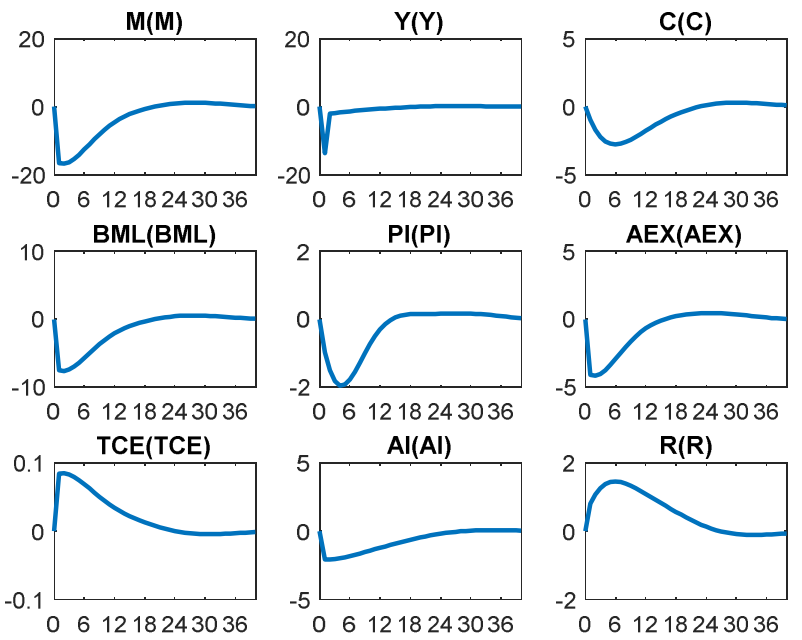

(Monetary policy shock).
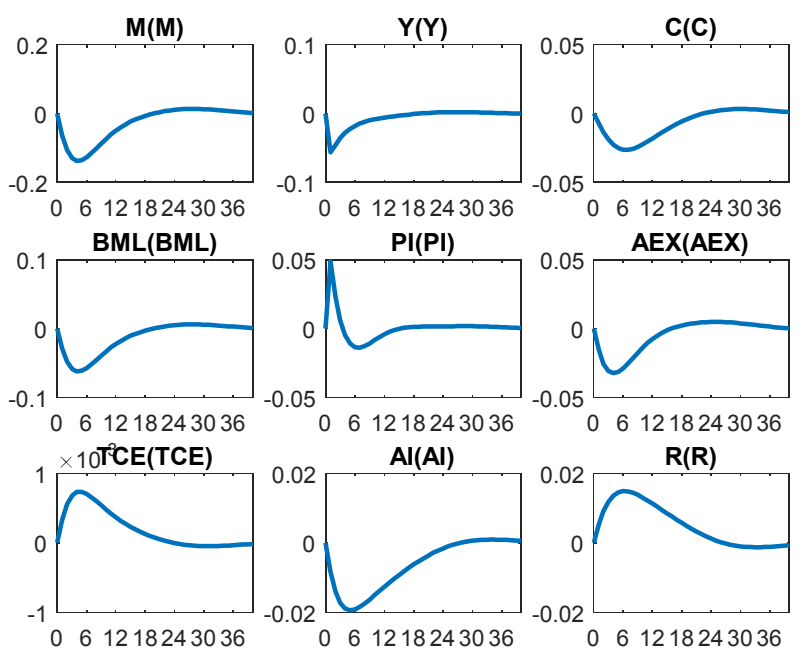

(Inflationary shock).
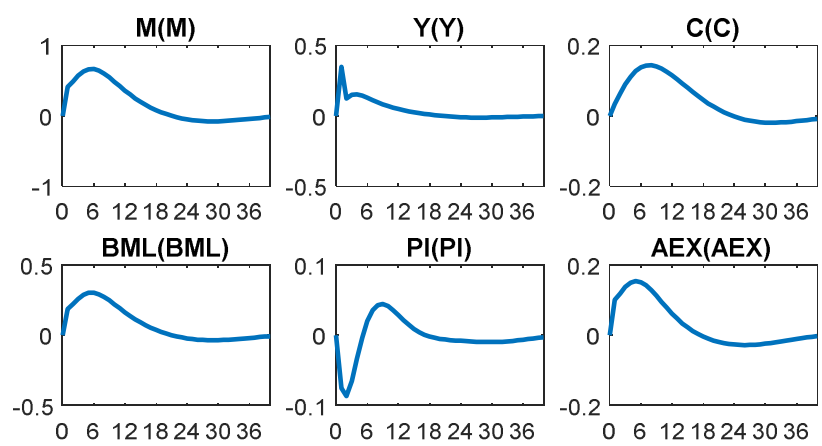

$\mathrm{PI}(\mathrm{PI})$
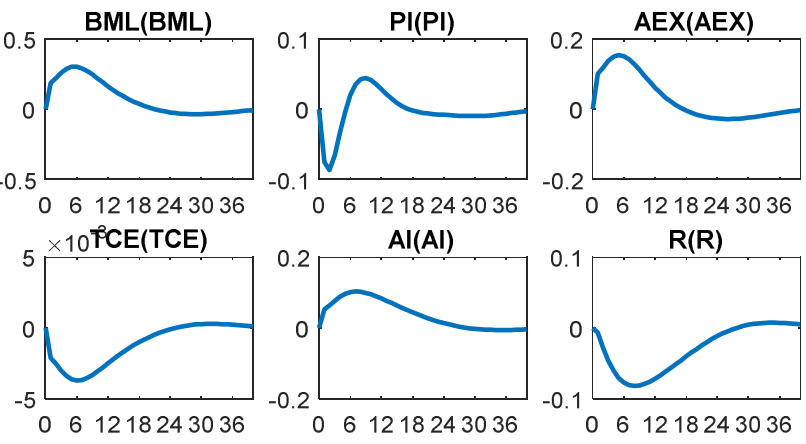

(Productivity shock).

Source: Simulations under RISE ${ }^{16}$.

Figure 1. Impulse response functions in a standard environment.

The impulse response functions above show that an oil shock decreases external reserves and, as a result, reduces the broad monetary base that appears on the liabilities side of the central bank's balance sheet. Concomitantly, the domestic commitments of the central bank contracts. Due to the reduction of the monetary base and the credit multiplier/divisor mechanism, the money supply contracts and induces a reduction of the inflationary tensions. Since production takes advantage of the ability to change prices according to the Calvo (1983) principle, there is a decrease in price and consumption. A paradoxical dynamic that we can highlight is that of the external coverage ratio of the currency that goes back up. This is attributable to the modelling of external assets as a reliance on past oil prices. As a reaction, a tightening of monetary conditions may be necessary.

The tightening of monetary conditions and the inflationary shock reproduce the same dynamics described above, with smaller amplitudes. The monetary policy shock confirms the rise in the key rate following an oil shock, because of the dynamics of external reserves that appear in the monetary rule. Likewise, the inflationary shock induces a rise in this key rate and, by a training effect, the other variables connected to it. The indirect mechanisms in action then make the effects of the inflationary shock less important than the monetary shock and even less so than the oil shock. The positive productivity shock will improve production and consumption and, in turn, lead to a decrease in inflation and therefore in the key rate. At the same time, the increase in production will lead to the increase in external assets, starting from the balance of payments and hence from the monetary base; this will lead to an increase in the money demand and a resurgence of inflationary pressures. The increase in the monetary base in the broad sense

16 Rationality in Switching Environment, a toolbox by Junior Maih. 
(stronger than the external assets) appearing in the denominator of the coverage rate will induce a decrease of this one.

\subsection{Macroeconomic Effects in the Presence of Strong / Low Constraint Occurrence Probabilities (0.9/0.05): Fixed Output Probability at 0.5}

We assume here that only the probability of occurrence of the choc can vary. The probability of exiting remain at 0.5 . The simulation will therefore consist of reducing the probability of occurrence from a high-assumed level (0.9) to a low level (0.05) and examining the resulting effects.
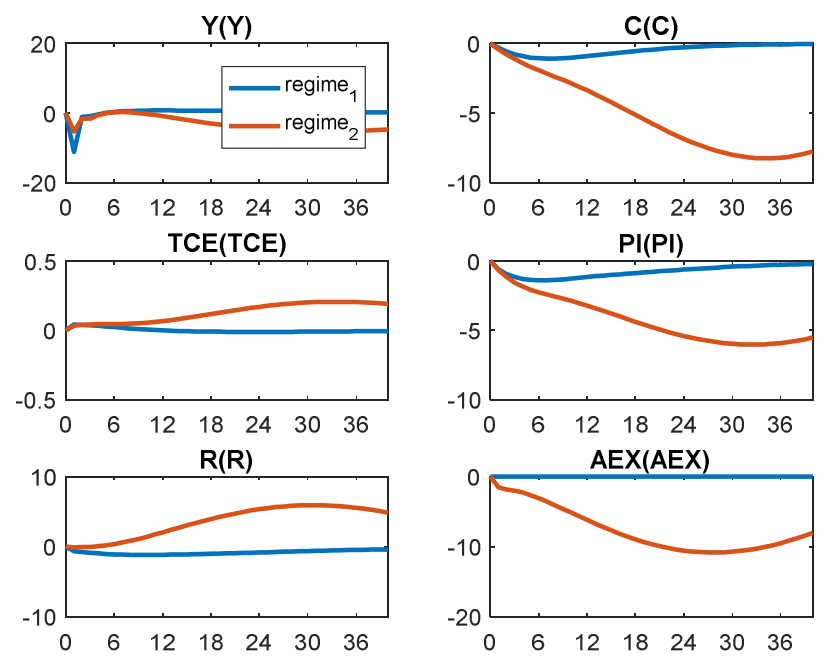

High probability (entry 0.9 and exit 0.5 ).
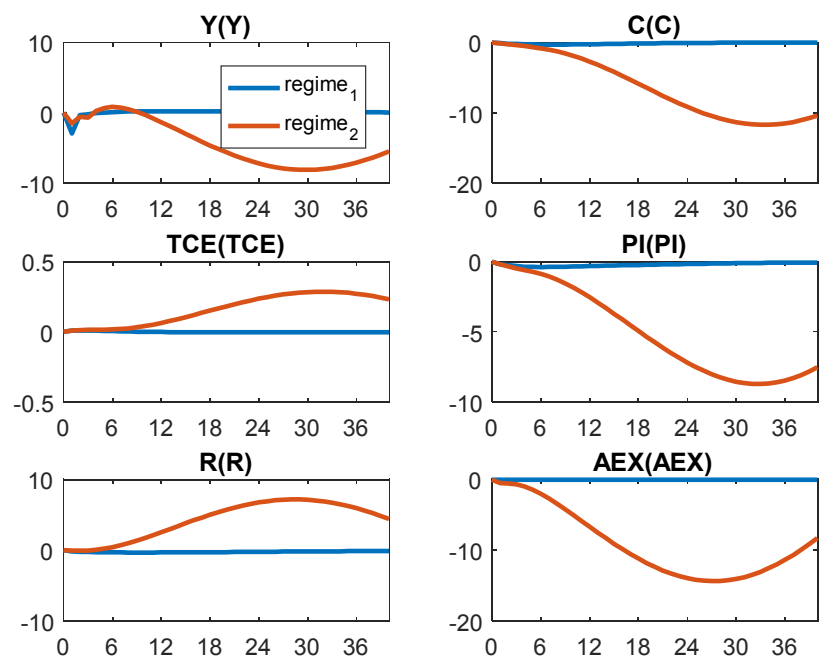

Low probability (exit 0.05 and exit 0.5 ). Source: Simulations under RISE.

Figure 2. Impulse response functions in a dual-regime environment following an oil shock.

The high probability of the constraint binding imposes the central bank to focus solely on the reconstitution of external reserves. Thus, notwithstanding a drop in inflation, consumption, output and a rise in the external coverage rate, the tightening of monetary conditions is attributable here to the decline in external reserves. This fear of the occurrence of the constraint remain even in the presence of low probabilities, notwithstanding the low impact on consumption, the significant deceleration of inflationary pressures, the significant fall in activity and a greater rise in the external coverage rate of the currency.
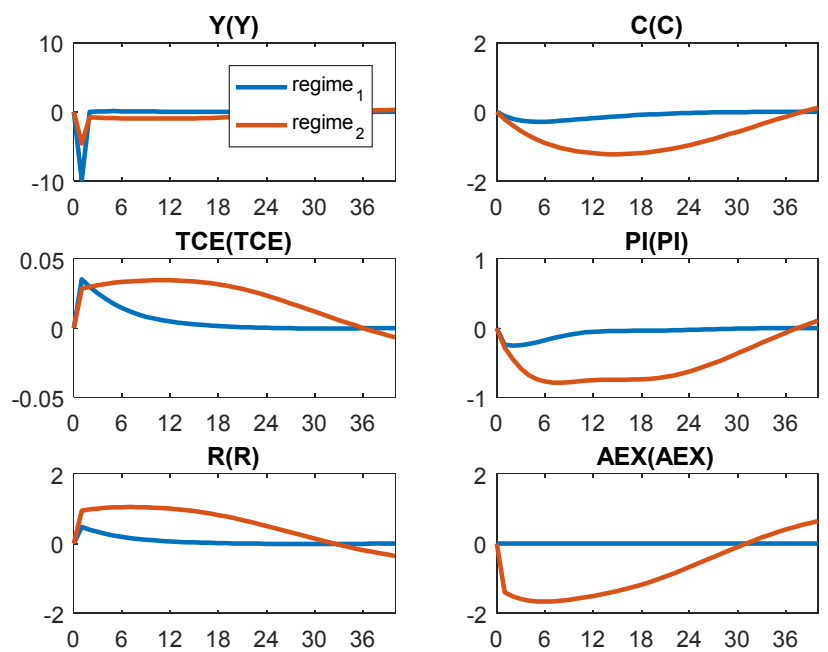

High probability (entry 0.9 and exit 0.5 ).
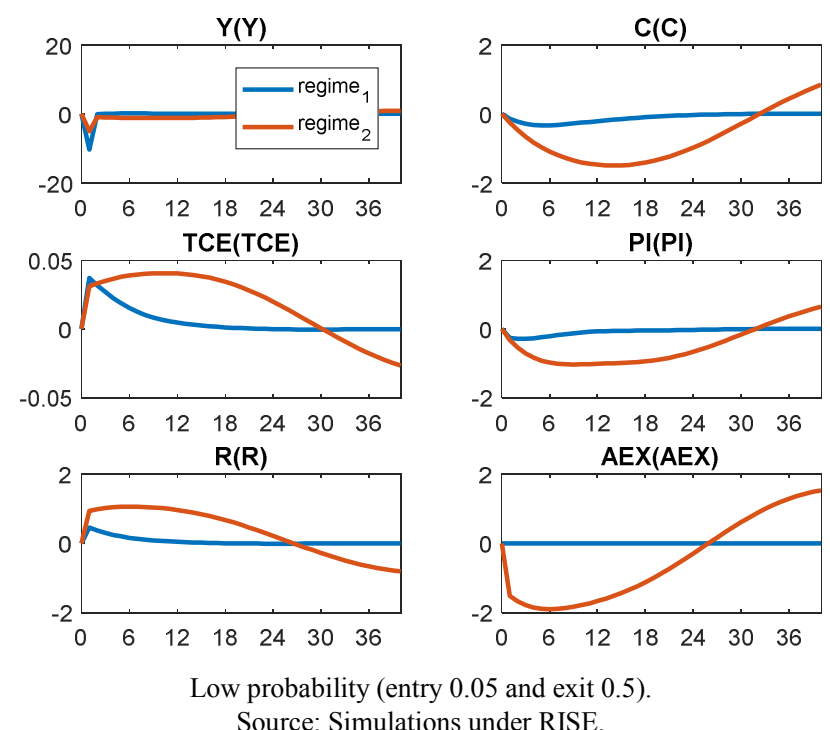

Figure 3. Impulse response functions in a dual-regime environment following a monetary policy shock.

The observation of the reaction functions above shows that a monetary shock gives them the same dynamics, whether the probability of occurrence of the constraint on external reserves is high or low. These effects seems large at the end of the simulation period when the probability of occurrence of the shock is low.

In the event of an inflationary shock, the effect on inflation remains the same, whether the probability of occurrence of the constraint on reserves is high or low. The tightening of monetary conditions appears to be somewhat similar in both cases, as are the effects on consumption, production, external reserves and the external coverage rate of currency. However, 
these effects seems large at the end of the simulation for the low probability that the constraint bind, due to the relaxation induced by this weakness of the probability. Such an observation shows that, in the presence of an inflationary shock, even if the BEAC gives primacy to the external counterpart of its objective, the inner counterpart remains almost satisfied.
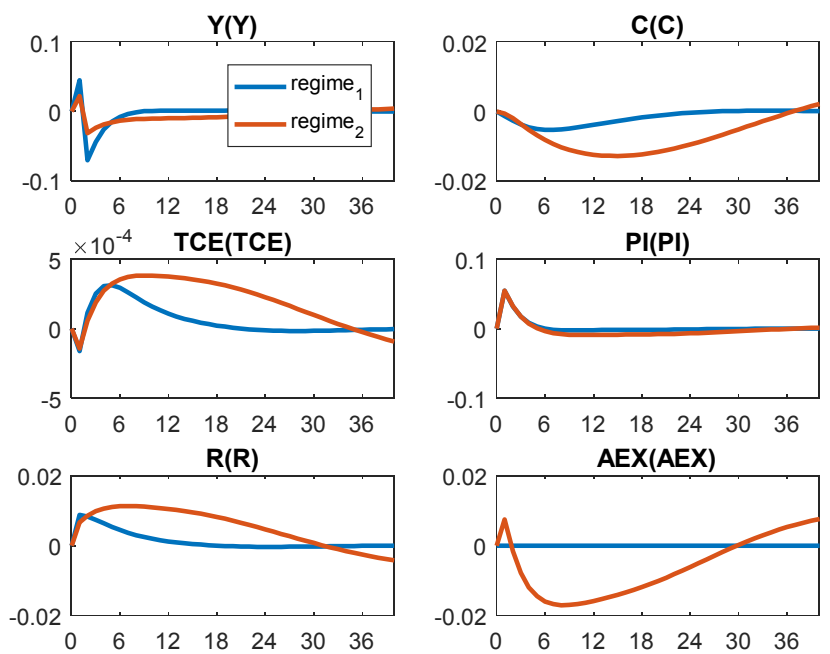

High probability (entry 0.9 and exit 0.5 ).
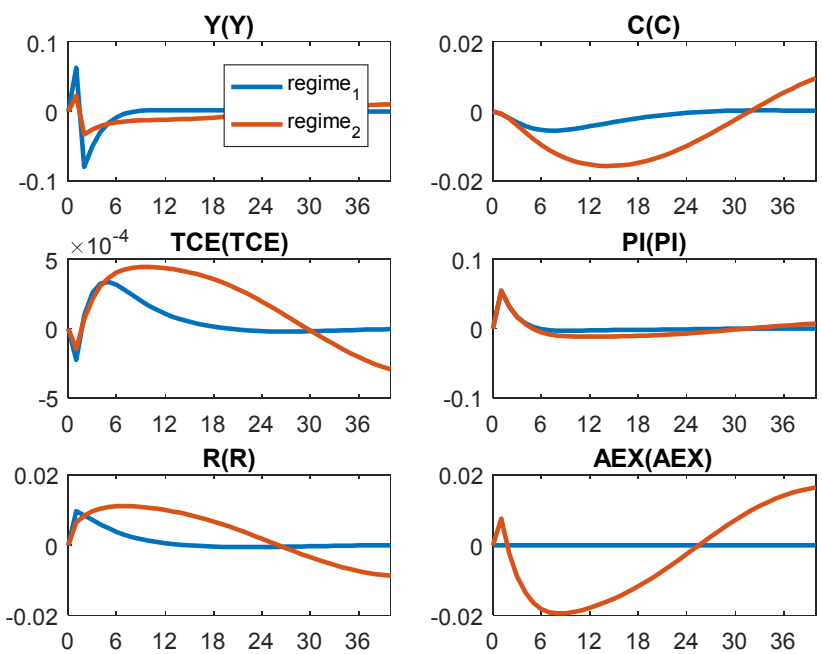

Low probability (entry 0.05 and exit 0.5 ).

Source: Simulations under RISE.

Figure 4. Impulse response functions in a two-regime environment following an inflation shock.

\subsection{Macroeconomic Effects in the Presence of Strong / Low Exit Probabilities (0.9 / 0.05): Entry Probability Fixed at 0.5}

We assume here that only the probability of exit from the constraint can vary. The probability of entering remain at 0.5 . The simulation will therefore consist in increasing the probability of exit from a supposed high level (0.9) to a low level (0.05) and in examining the resulting macroeconomic effects.

An examination of the graphs above shows that when the probability of leaving the constraint is high, the central bank adopts a somewhat passive behaviour, with a late reaction. The main consequence is the appearance of imbalances several periods after the occurrence of the shock, in particular because of the impact of the modelling of oil prices termed futures. On the other hand, when the probability of exit from the oil shock is low, the central bank reacts immediately, which makes it possible to control its effects somewhat. Ultimately, there is the need to control the occurrence of shocks.
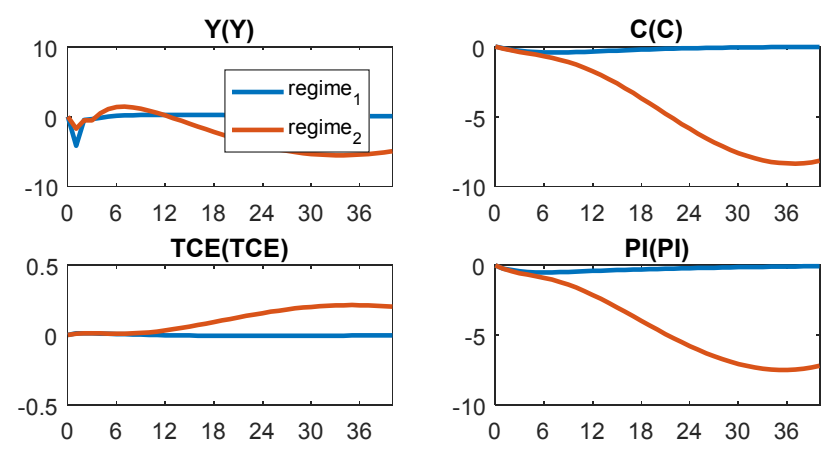

$\mathrm{PI}(\mathrm{PI})$

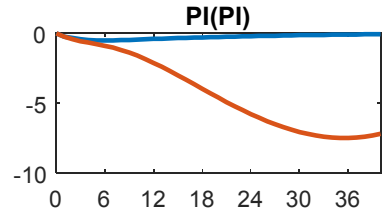
$\mathbf{R}(\mathbf{R})$
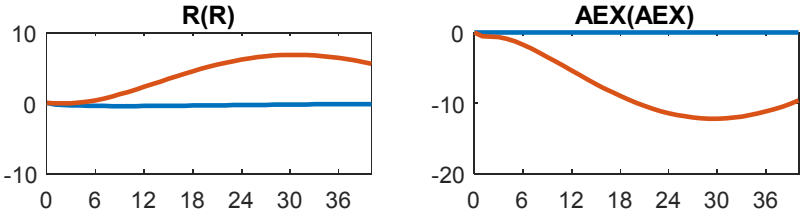

High probability $(0.5 / 0.9)$.
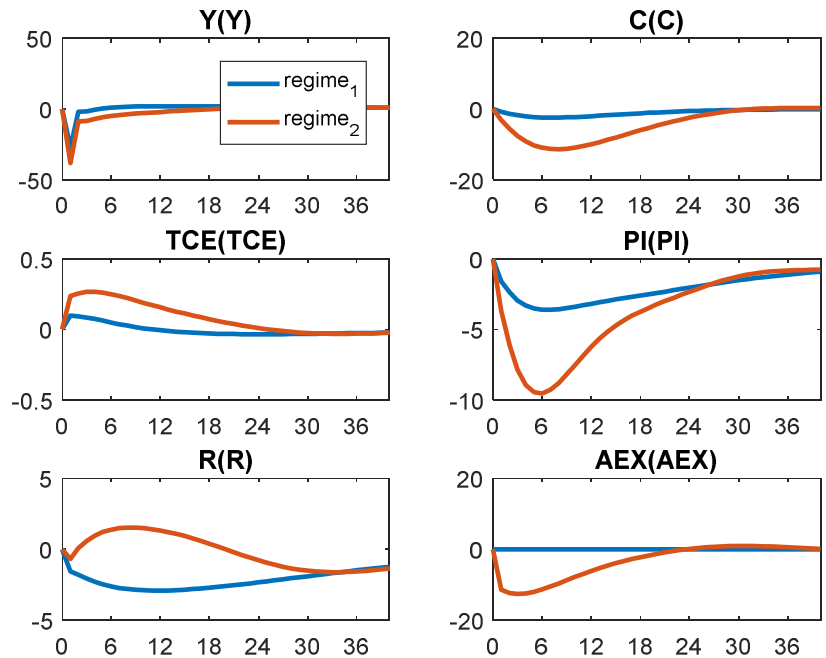

Low probability $(0.5 / 0.05)$.

Source: Simulations under RISE.

Figure 5. Response Functions in a Two-Model Environment Following an oil shock.

In the presence of a high probability of exit from the constraint, a monetary policy shock has identical effects on the product in the two regimes. The effects on the other variables seems to be large in the second regime. When the probability of exit is low, the reactions of the variables exhibit the same dynamics than a high probability of exit of the shock. 

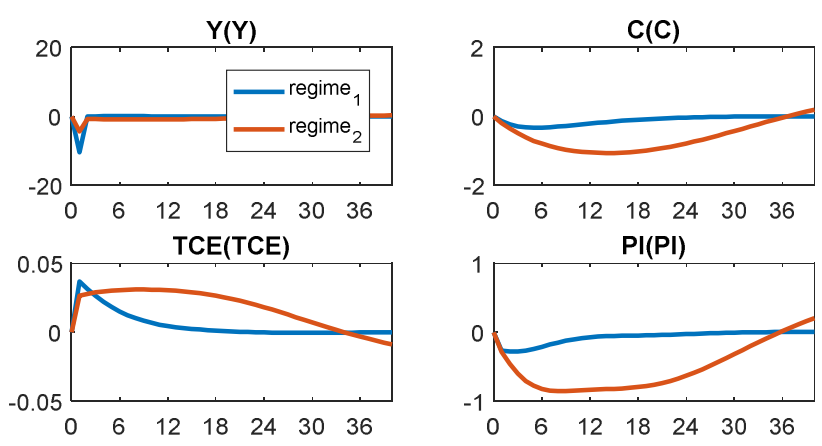

$\mathbf{R}(\mathbf{R})$

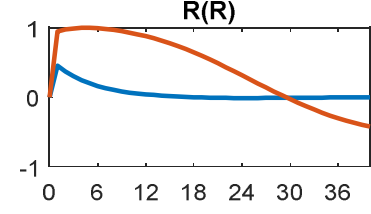

High probability $(0.5 / 0.9)$.
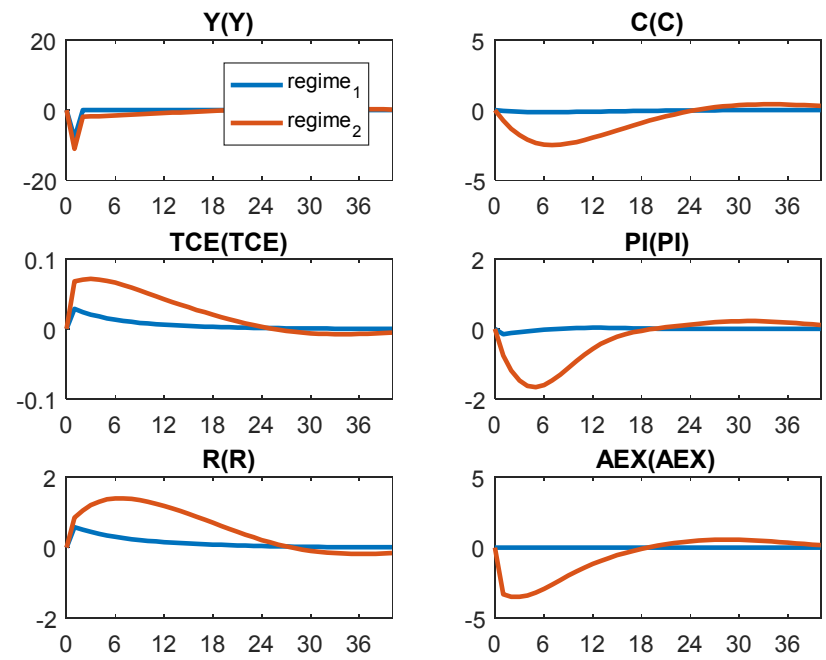

Low probability $(0.5 / 0.05)$.

Source: Simulations under RISE.

Figure 6. Impulse response functions in a two-regime environment following a monetary policy shock.
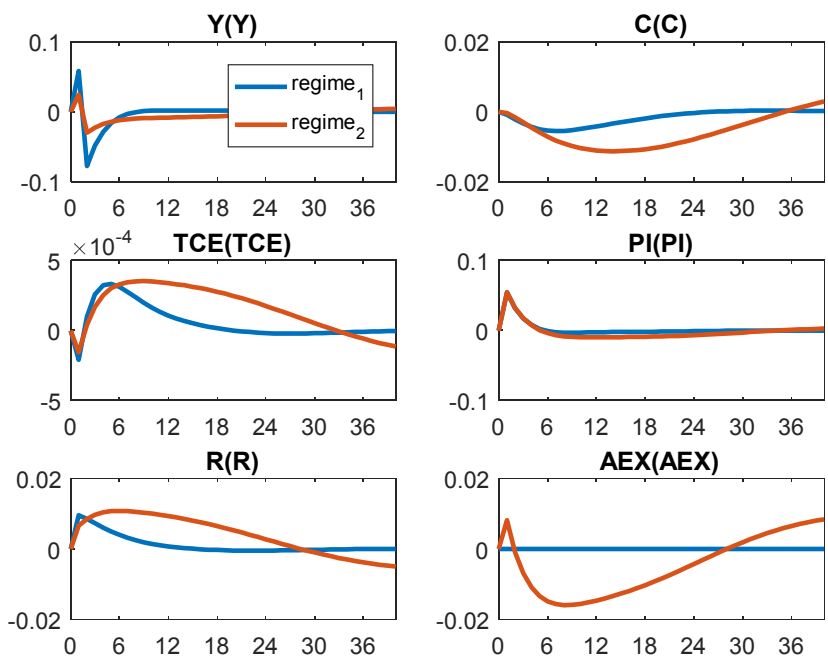

High probability $(0.5 / 0.9)$.
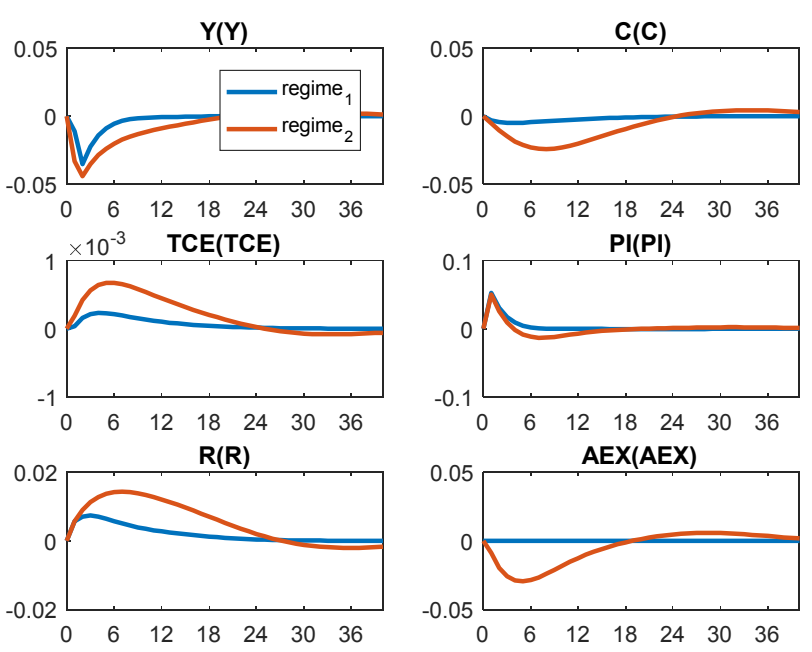

Low probability $(0.5 / 0.05)$.

Source: Simulations under RISE.

Figure 7. Impulse response functions in a two-regime environment following an inflation shock.

The effects of an inflationary shock do not differ greatly for many variables, whether the probability of the occurrence the constraint is high or not.

From all the foregoing, one may be inclined to question BEAC's degree of commitment to defend its anchoring when the underlying constraint bind because of numerous undesirable effects that arise. However, it is essentially to note that these effects are more the result of the structural characteristics of the zone than the monetary arrangements emerging from the cooperation framework with the French Treasury. Indeed, the impact of oil shocks on foreign reserves dynamics would be smaller if the economies concerned were not as dependent on oil resources. The reversibility of this impact can arise under certain conditions that we examine below if the central bank had the possibility of allowing its currency to depreciate against the dollar. In this context and assuming transferred the EUR/\$ correlation as shown in Annex Appendix 5 to the $\mathrm{XAF} / \$$ relationship, the dollars received from oil exportation would yield more CFA francs.

However, other elements need to be account when analysing the effects of a voluntary depreciation. The cost of imports in dollars need to be balance with the factors responsible for the positive correlation between the dollar and the euro on the other hand. Indeed, due to the rigidity of imports, the above foreign exchange gain could be cancelled and, it is unlikely that the factors responsible for the EUR/\$ dynamics would be identical for the $\mathrm{XAF} / \$$ dynamics. In other words, there may be no correlation, especially since CEMAC exports appears less diversified than Euro zone. Further diversification would mean that the central bank reacts less strongly and gives the economies some stability. This approach, which sees money as "the reflection of an economy," in no way rules out the idea of giving monetary policy a little more flexibility in pegging to a basket of currencies, for example. It simply highlights the dangers of hopping to grow, while depending 
on a product whose price is both volatile and uncontrolled.

\section{Conclusion}

This study questioned macroeconomic effects of the BEAC commitment to ensure its nominal anchoring when the underlying external reserves constraint occurs. External reserves appears in the second half of its objective. When their level falls below a threshold comparable to their long run trajectory, monetary policy decisions are taken mainly with a view to the reconstituting the level of foreign reserves, so that they are compatible with three months of imports of goods and services as well as the servicing of short-term debt. To analyse the resulting macroeconomic effects, we postulated two scenarios. The first one varies the probability of occurrence of the constraint by keeping fixed the one of leaving it. The second freezes the probability of occurrence of the constraint and examines the effects of a variation in the probability of non-occurrence of the constraint. As a result, it appeared that in a single-regime environment, an oil shock erodes external reserves, which results in a contraction of the broad monetary base: the liabilities side of the central bank's balance sheet. Concomitantly, the domestic commitments of the central bank contracts. Due to the contraction of the monetary base and the dynamics of the multiplier/credit divider, the money supply contracts and induces a reduction of inflationary pressures. Since production takes advantage of the ability to change prices according to the Calvo (1983) principle, there is a decrease in price and consumption. Taking into account the constraint lead to a change in the above results.

Thus, when the probability of occurrence of the constraint is high, an oil shock pushes the central bank to concentrate solely on the reconstitution of external assets. In this regard, in the presence of a fall in inflation, consumption, or production, and a rise in the external coverage rate, the model advocates a tightening of monetary conditions, attributable to the decline in external reserves. This fear of the occurrence of the constraint remain even in the presence of low probabilities, notwithstanding the low impact on consumption, the significant deceleration of inflationary pressures, the significant fall in activity and a greater rise in the external coverage rate of currency. At the same time, reactions to monetary and inflationary shocks show identical profiles, whether the probability of occurrence of the shock is high or low. On the other hand, when the probability of nonoccurrence of the constraint is high, the central bank adopts a passive behaviour, with a late reaction. The main consequence is the appearance of imbalances several periods after the occurrence of the shock, in particular because of the impact of the modelling of oil futures prices. On the other hand, when the probability of nonoccurrence of the oil crisis is low, the central bank reacts immediately, which makes it possible to control its effects somehow. Ultimately, we posit the need to diversify the economies of the CEMAC Zone.

\section{Appendix}

\section{Appendix 1. The Dynamics of Internal and External Indicators of the Beac Monetary Policy Objective}

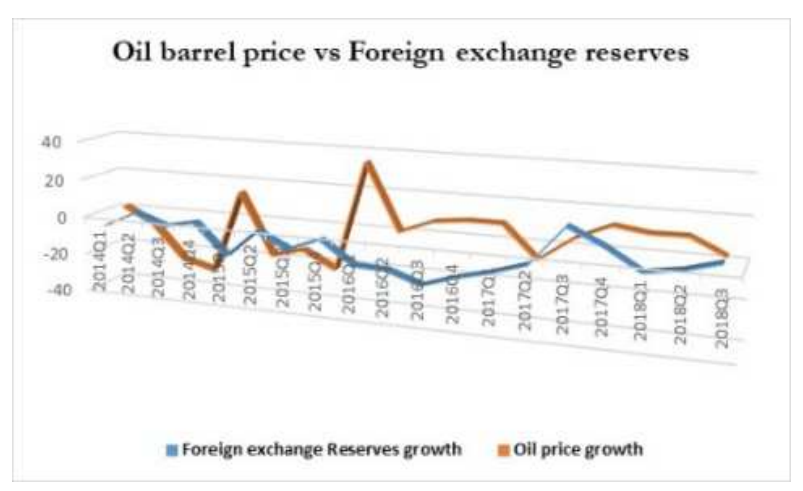

Figure 8. Evolution of oil barrel price and external reserves.

Source: the author.

1. Reserves are lagging behind with regards to the barrel price trend of;

2. Slopes appear less pronounced for reserves, evidence of the impact of other aggregates.

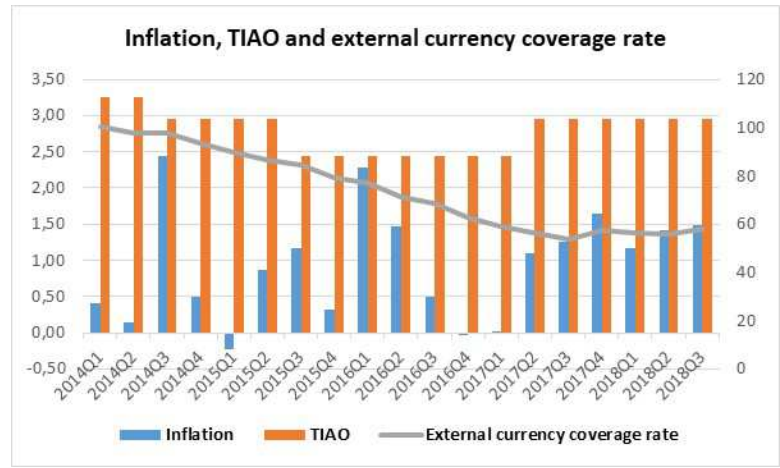

Figure 9. Dynamic of inflation, policy rate and external currency coverage rate.

Source: the author.

1. TIAO dynamics and coverage rate are positively correlated, nonetheless, there is a slight delay in coverage ratio;

2. Here we can consider a change of regime (EER or foreign assets).

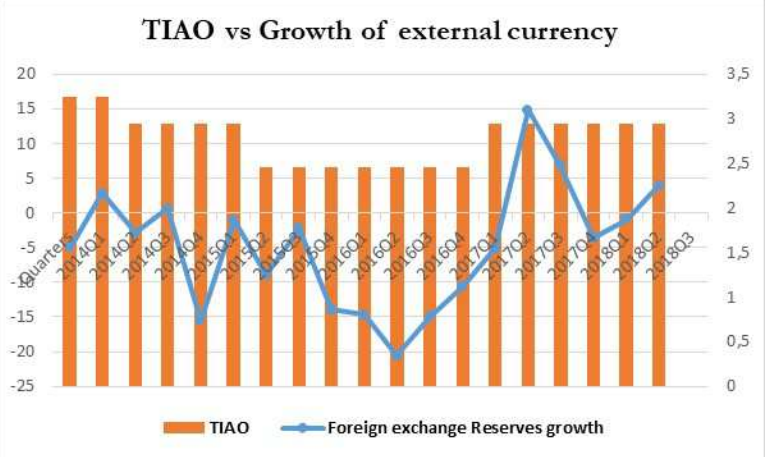

Figure 10. Evolution of the policy rate and the growth of external reserves

Source: the author.

1. The asset dynamics precede that of the TIAO of about three quarters.

2. The change of regime can apply to the dynamics of the assets. 


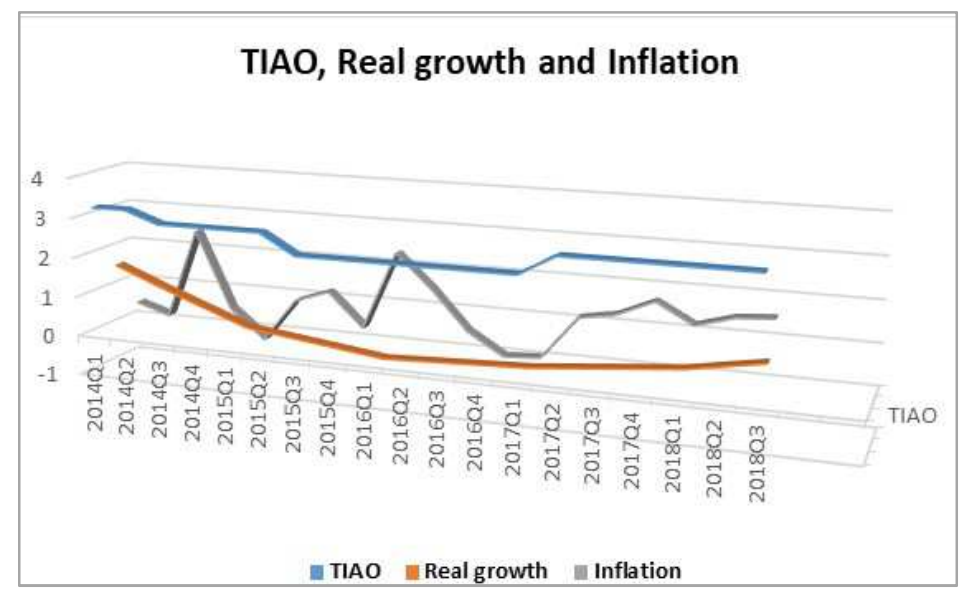

Figure 11. Dynamics of the policy rate, the real growth and inflation.

Source: the author.

1. Real growth seems to follow the trend of the TIAO.

2. Inflation proves more volatile.

3. Its rise corresponds to that of the TIAO, with a delay.

\section{Appendix 2. Log-Linearized Equations}

$$
\begin{gathered}
\hat{C}_{t}=\frac{h}{1+h} \hat{C}_{t-1}+\frac{1}{1+h} E_{t} \hat{C}_{t+1}-\frac{1-h}{1+h}\left(\hat{R}_{t}-E_{t} \hat{\pi}_{t+1}\right) \\
+\frac{1-h}{\sigma_{C}(1+h)}\left(\varepsilon_{t}^{C}-E_{t} \varepsilon_{t+1}^{C}\right) \\
\widehat{M}_{t}=\frac{\sigma_{C}}{\sigma_{M}}\left(\hat{C}_{t}-h \hat{C}_{t-1}\right)-\frac{1}{\sigma_{M}} \hat{R}_{t}+\hat{\pi}_{t}+\varepsilon_{t}^{M} \\
\hat{I}_{t}=\frac{1}{1+\beta} \hat{I}_{t-1}+\frac{1}{1+\beta} E_{t} \hat{I}_{t+1} \\
+\frac{\phi}{1+\beta} \hat{Q}_{t}-\frac{\beta E_{t} \varepsilon_{t+1}^{I}-\varepsilon_{t}^{I}}{1+\beta}
\end{gathered}
$$

$$
\begin{gathered}
\widehat{W}_{t}=\frac{\beta}{1+\beta} E_{t} \widehat{W}_{t+1}+\frac{1}{1+\beta} \widehat{W}_{t-1}+\frac{\beta}{1+\beta} E_{t} \hat{\pi}_{t+1}-\frac{1+\beta \gamma_{W}}{1+\beta} \widehat{\pi}_{t}+\frac{\gamma_{W}}{1+\beta} E_{t} \hat{\pi}_{t+1} \\
-\frac{1}{1+\beta} \frac{\left(1-\beta \xi_{W}\right)\left(1-\xi_{W}\right)}{\left(\frac{\left(1+\left(1+\lambda_{W}\right) \sigma_{L}\right)}{\lambda_{W}}\right)} \xi_{W}\left[\widehat{W}_{t}-\sigma_{L} \widehat{L}_{t}-\frac{\sigma_{C}}{1-h}\left(\hat{C}_{t}-h \hat{C}_{t-1}\right)-\varepsilon_{t}^{L}-\varepsilon_{t}^{W}\right]
\end{gathered}
$$$$
\widehat{L}_{t}=-\widehat{W}_{t}+(1+\psi) \hat{R}_{t}^{K}+\widehat{K}_{t-1}
$$$$
\hat{Y}_{t}=\left(1-\tau \frac{K_{S S}}{Y_{S S}}-\frac{G_{S S}}{Y_{S S}}-\right) \hat{C}_{t}+\tau \frac{K_{S S}}{Y_{S S}} \hat{I}_{t}+\frac{G_{S S}}{Y_{S S}} \varepsilon_{t}^{G}
$$$$
=\varphi \varepsilon_{t}^{A}+\varphi \alpha \widehat{K}_{t-1}+\varphi \alpha \psi \hat{R}_{t}^{K}+\varphi(1-\alpha) \hat{L}_{t}
$$$$
\hat{R}_{t}=\rho_{R} \hat{R}_{t-1}+\left(1-\rho_{R}\right)\left[\rho_{\pi}\left(\hat{\pi}_{t}-\pi_{s s}\right)+\rho_{Y} \hat{Y}_{t}-\rho_{A E x} \widehat{A E x_{t}}\right]
$$

$$
+L M+\varepsilon_{t}
$$

$$
\begin{aligned}
\widehat{C C}_{t}=a_{1} \frac{R P_{S S}}{C C_{S S}} \widehat{R P}_{t}+\left(1-a_{1}\right) \frac{A U T_{S S}}{C C_{S S}} \widehat{A U T_{t}} \\
\widehat{R P}_{t}=a_{1} \frac{Y P_{S S} P P_{S S}}{R P_{S S}}\left(\widehat{Y P_{t-1}}+\widehat{P P_{t-2}}\right) \\
+\left(1-a_{1}\right) \frac{A U T_{S S}}{C C_{S S}} \widehat{A U T_{t}} \\
\widehat{P P}_{t}=c_{1} \widehat{P P_{t-1}}+\varepsilon_{T}^{P P} \\
\widehat{C K}_{t}=a_{2} \widehat{C K_{t-1}}+\varepsilon_{T}^{C K} \\
\widehat{A U T}_{t}=\rho_{A U T} A \widehat{U T_{t-1}}+\varepsilon_{T}^{A U T}
\end{aligned}
$$




$$
\widehat{A I}_{t}=b_{1} \widehat{A I_{t-1}}+\left(1-b_{1}\right) \widehat{Y}_{t}+\varepsilon_{T}^{A I}
$$

Stochastic Processes

$$
\begin{aligned}
& E \widehat{P S_{-} C_{t}}=\rho_{E P S_{-} C} E P{\widehat{P S_{-} C_{t-1}}}_{t}+\varepsilon_{t}^{E P S_{-} C} \\
& E{\widehat{P S \_} A_{t}}=\rho_{E P S_{-} A} E P \widehat{S \_}_{t-1}+\varepsilon_{t}^{E P S_{-} A} \\
& E{\widehat{P S} \pi_{t}}_{t}=\rho_{E P S_{-} \pi} E P{\widehat{S S_{-}}}_{t-1}+\varepsilon_{t}^{E P S_{-} \pi} \\
& E \widehat{P S_{-} Q_{t}}=\rho_{E P S_{-} Q} E \widehat{P S_{-} Q_{t}}+\varepsilon_{t}^{E P S_{-} Q} \\
& E{\widehat{P S} L_{t}}_{t}=\rho_{E P S_{-} L} E P{\widehat{P S_{-} L_{t-1}}}+\varepsilon_{t}^{E P S_{-} L} \\
& E \widehat{P S_{-} G_{t}}=\rho_{E P S_{-} G} E{\widehat{P S_{-} G_{t}}}_{t}+\varepsilon_{t}^{E P S_{-} G} \\
& E \widehat{P S \_C} K_{t}=\rho_{E P S_{-} C K} E P{\widehat{S \_} C K_{t-1}}+\varepsilon_{t}^{E P S_{-} C} \\
& E \widehat{P S_{-} P} P_{t}=\rho_{E P S_{-} P P} E \widehat{P S_{-} P} P_{t}+\varepsilon_{t}^{E P S_{-} P P} \\
& E{\widehat{P S \_} M_{t}}=\rho_{E P S_{-} M} E P{\widehat{S \_} M_{t-1}}_{t}+\varepsilon_{t}^{E P S_{-} M}
\end{aligned}
$$

\begin{tabular}{|c|c|c|}
\hline Parameters & Significations & Values \\
\hline $\mathrm{h}$ & Habits consumption parameter & 0,86 \\
\hline$\sigma_{C}$ & $\begin{array}{l}\text { Inverse of elasticity of consumption } \\
\text { substitution }\end{array}$ & 5,62 \\
\hline$\sigma_{M}$ & $\begin{array}{l}\text { Parameter of interest rate in money } \\
\text { demand }\end{array}$ & 0,4 \\
\hline$\beta$ & Discount parameter & 0,91 \\
\hline$\delta$ & Depreciation rate of capital & 0,025 \\
\hline ksi & Inverse of cost function in investment & 0,25 \\
\hline$\gamma_{P}$ & Price indexation parameter & 0,8 \\
\hline$\xi^{P}$ & Calvo (1983) probability for prices & 0,8 \\
\hline$\alpha$ & $\begin{array}{l}\text { Capital parameter in Cobb-Douglas } \\
\text { function }\end{array}$ & 0,3 \\
\hline$\gamma_{W}$ & Indexation parameter for wages & 0,9 \\
\hline$\xi^{W}$ & Calvo (1983) parameter for wages & 0,8 \\
\hline$\lambda_{W}$ & Mark-up for wages & 0,8 \\
\hline$\sigma_{L}$ & Labour elasticity of substitution & 2,5 \\
\hline$\psi$ & $\begin{array}{l}\text { Fix cost in the production function plus } \\
\text { one }\end{array}$ & 1,2 \\
\hline$\rho_{R}$ & $\begin{array}{l}\text { Smooth parameter in the augmented } \\
\text { Taylor rule }\end{array}$ & 0,9 \\
\hline$\rho_{\pi}$ & $\begin{array}{l}\text { Inflation parameter in the augmented } \\
\text { Taylor rule }\end{array}$ & 1,2 \\
\hline$\rho_{Y}$ & $\begin{array}{l}\text { Output gap parameter in the augmented } \\
\text { Taylor rule }\end{array}$ & 0,5 \\
\hline$\rho_{A E X}$ & $\begin{array}{l}\text { External reserve gap parameter in the } \\
\text { augmented Taylor rule }\end{array}$ & 1,5 \\
\hline$a_{1}$ & Ratio of oil revenue to capital account & 0,8 \\
\hline$a_{2}$ & $\begin{array}{l}\text { Autoregressive parameter of capital } \\
\text { account balance }\end{array}$ & 0,9 \\
\hline $\mathrm{b}_{1}$ & $\begin{array}{l}\text { Autoregressive parameter of domestic } \\
\text { assets }\end{array}$ & 0,85 \\
\hline$c_{1}$ & Autoregressive parameter of oil price & 0,95 \\
\hline xteur & Monetary multiplier & 2,01 \\
\hline Kss & Capital at steady state & 2,1 \\
\hline R_Kss & Return on capital at steady state & 1,001 \\
\hline Gss & Public expenditures at steady state & 1,05 \\
\hline Yss & GDP at steady state & 10,02 \\
\hline Y_Pss & Oil GDP at steady state & 17,68 \\
\hline $\mathrm{R} \overline{\mathrm{P}}_{\mathrm{SS}}$ & Oil revenue at steady state & 30,02 \\
\hline PIss & Quarterly inflation target & 0,75 \\
\hline AEXss & External reserves at steady state & 29,72 \\
\hline BMLss & Broad monetary base at steady state & 21,96 \\
\hline AIss & Domestic assets at steady state & 21,2 \\
\hline ENGss & Liabilities at steady state & 20,42 \\
\hline
\end{tabular}

\begin{tabular}{|c|c|c|}
\hline Parameters & Significations & Values \\
\hline CCss & Current account at steady state & 0,99 \\
\hline CKss & $\begin{array}{l}\text { Capital account and financial operations at } \\
\text { steady state }\end{array}$ & 28,73 \\
\hline PPss & Oil price at steady state & 12,63 \\
\hline AUTss & $\begin{array}{l}\text { Other elements of current account at } \\
\text { steady state }\end{array}$ & $-29,03$ \\
\hline TCEss & $\begin{array}{l}\text { Coverage ratio of external reserves at } \\
\text { steady state }\end{array}$ & 55 \\
\hline Mss & Money at steady state & 20,01 \\
\hline
\end{tabular}

\section{Appendix 3. Summary Table of Model Parameters}

Table 1. Structural parameter of the model.
Appendix 4. Likelihood of the Model in a One-Regime Environment
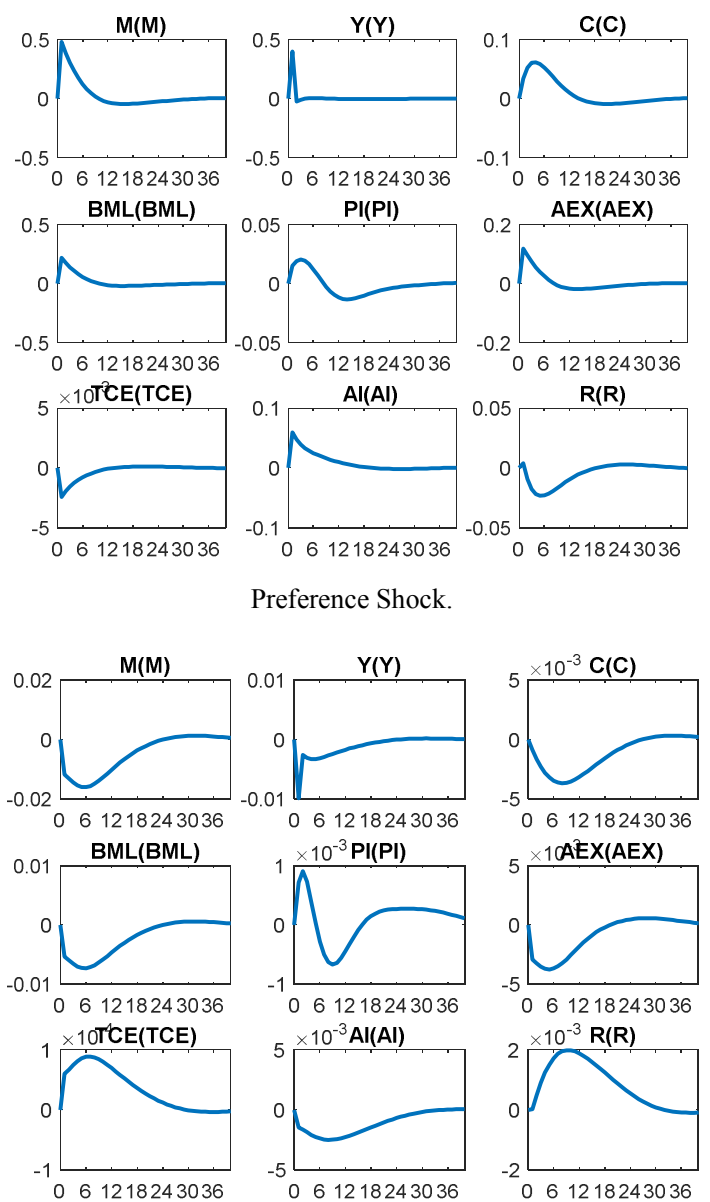

Wage rate Shock.
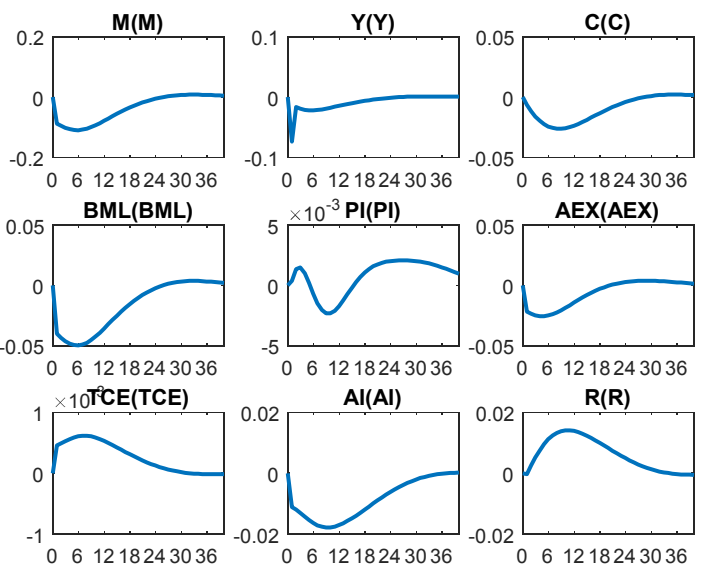

Labour hours shock. 

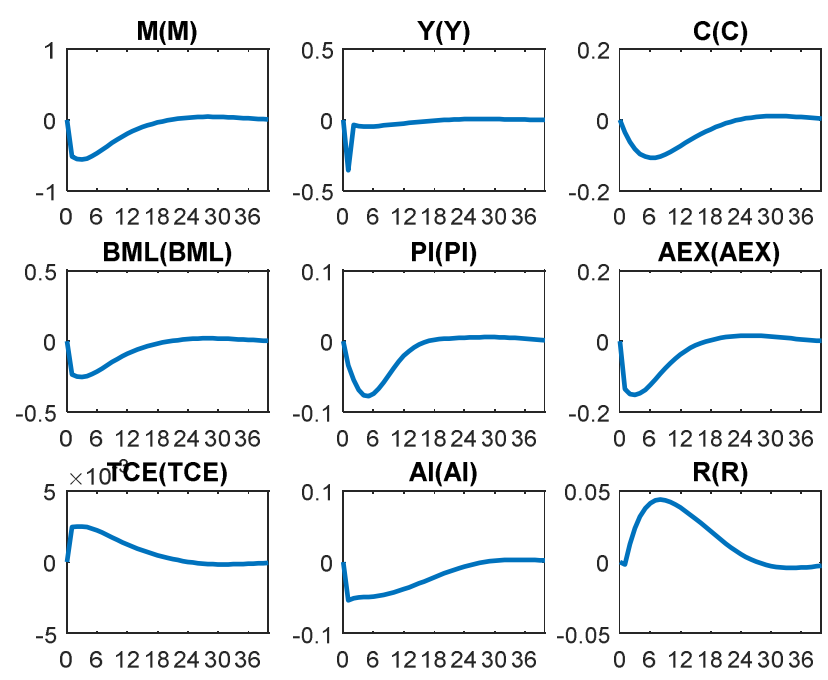

Public expenditures shock.
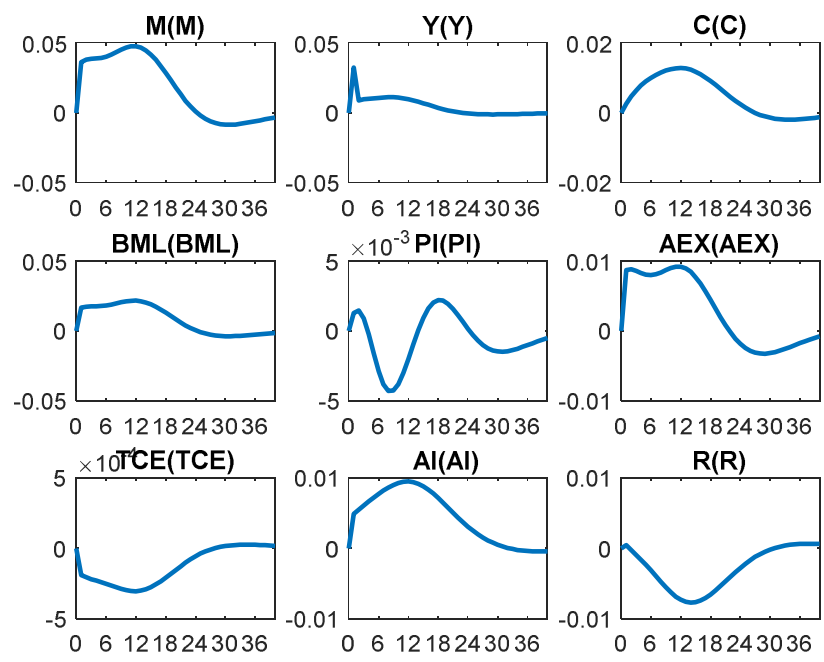

Investment shock.
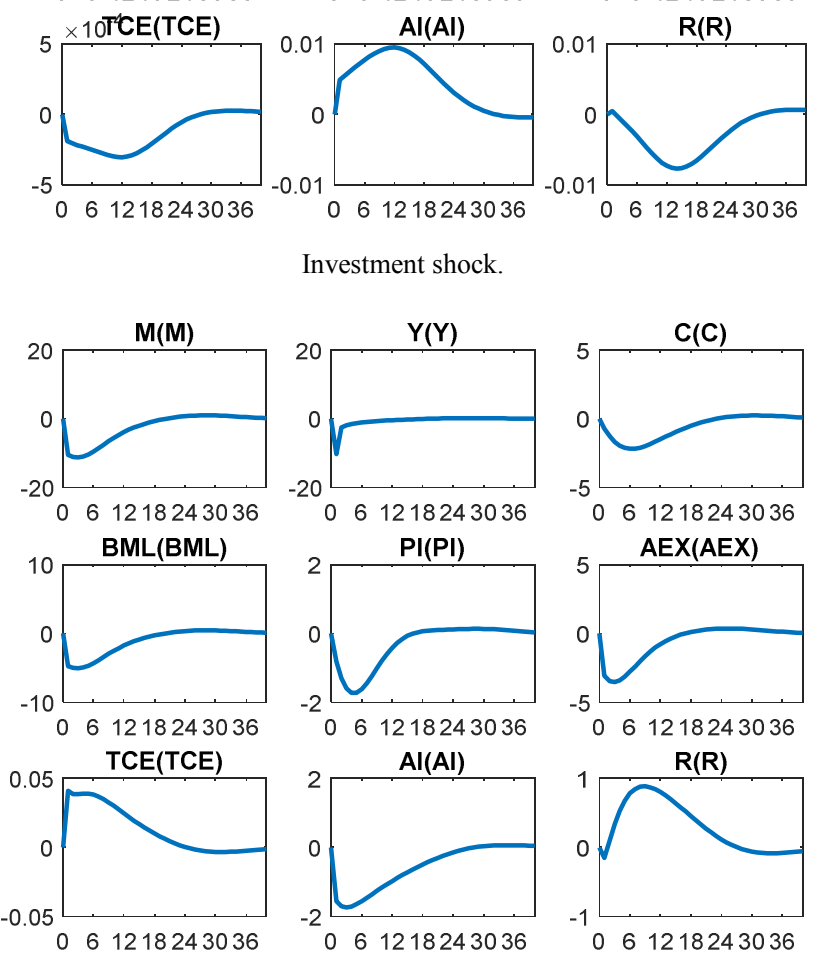
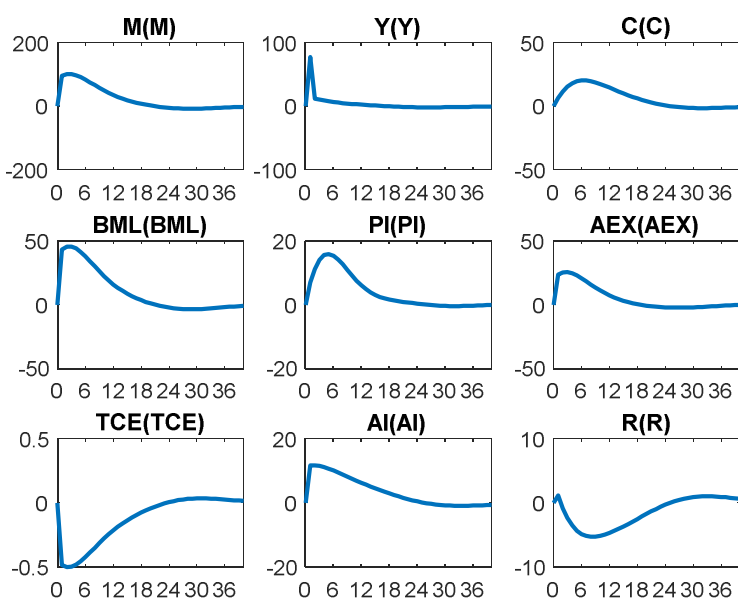

$$
\text { Source: }
$$

Capital account shock

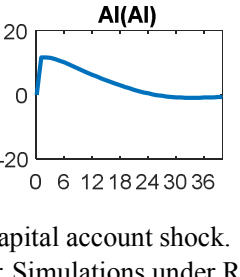

Figure 12. Impulse response functions in a one regime model

Appendix 5. Monthly Changes in Exchange Rates (EUR / Sor \$ / EUR) and Barrel Rate in Dollars Between 2013 and 2018

\section{Appendix 5.1. Evolution of the Exchange Rate to Certain}

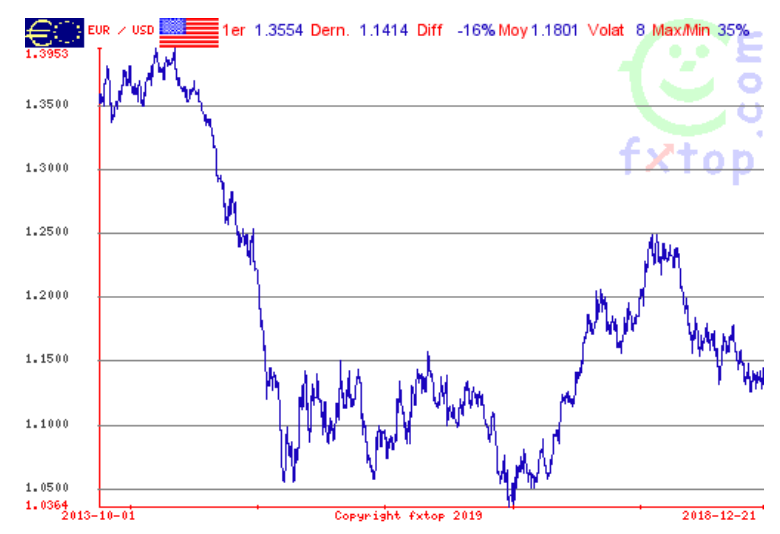

Source: Fxtop.com (dollars per Euro).

Figure 13. Dynamic of exchange rate to certain

Appendix 5.2. Evolution of the Exchange Rate to Uncertain

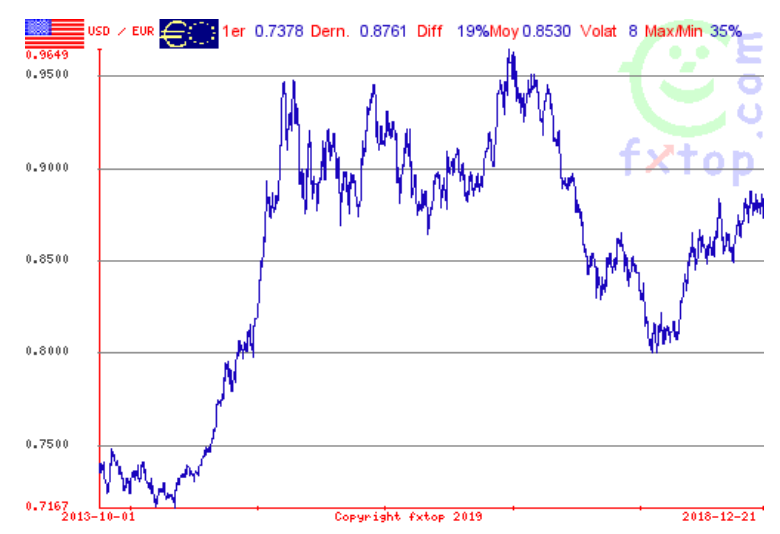

Source: Fxtop.com (Euros per dollar).

Figure 14. Dynamic of exchange rate to uncertain 


\section{Appendix 5.3. Evolution of the Price of Barrel in Dollars}

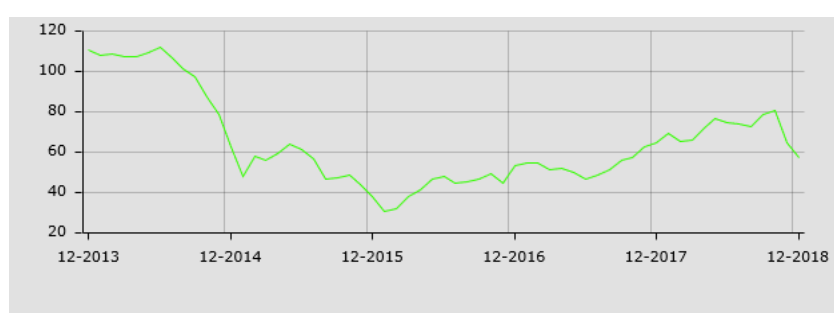

Source: Comité National Routier (France).

Figure 15. Dynamic of oil price in dollars

\section{References}

[1] Direction de la Recherche (2017), "Les déterminants de la dynamique des réserves de change dans la CEMAC de janvier 2016 à septembre 2017", Note d'Etude.

[2] Mvondo T. (2018), "La pertinence du TIAO comme instrument de politique monétaire de la BEAC: Fondements théoriques et évaluation empirique", BEAC Working Paper.

[3] Taylor J. B. (1993), "Discretion versus Policy Rules in Practice", Carnegie Rochester Conference Series on Public Policy, December 1993b, 39, pp. 195--214.

[4] Lucas R. J. (1976), "Econometric policy evaluation: A critique", Carnegie-Rochester Conference Series on Public Policy, 1 (1), 19-46.

[5] Binning A., and Maih J. (2017), "Modelling Occasionally Binding Constraints Using Regime-Switching”, Norges Bank Research Working Paper.

[6] Brzoza-Brzezina M., Kolasa M., and Makarski K. (2015), “A penalty function approach to occasionally binding credit constraints". Economic Modelling, 51 (C), 315-327.

[7] Gertler M. and Karadi P. (2011), "A model of unconventional monetary policy”, Journal of Monetary Economics 58.1, pp. $17-34$.

[8] Christiano L., Rostagno M. and Motto R. (2010), "Financial factors in economic fluctuations", Working Paper Series 1192. European Central Bank.

[9] Kiyotaki N. and Moore J. (2012), "Liquidity, Business Cycles, and Monetary Policy", NBER Working Papers 17934. National Bureau of Economic Research, Inc.

[10] Shi S. (2015), "Liquidity, assets and business cycles", Journal of Monetary Economics 70.0, pp. 116-132.

[11] Bigio S. (2017), "Liquidity shocks and the business cycle: What next", European Economic Review, Elsevier, Vol. 97 (C), pp. 108-130.

[12] Kiyotaki N. and Moore J. (1997), "Credit Cycles", Journal of Political Economy, vol. 105, n².

[13] Iacoviello M. (2005), "House prices, borrowing constraints, and monetary policy in the business cycle", American Economic Revue, 95 (3), 739-764.

[14] Liu Z., P. Wang and T. Zha (2013), "Land-price dynamics and macroeconomic fluctuations", Econometrica 81 (3), 1147-
1184.

[15] Blanchard O. J., and Khan C. M. (1980), "The Solution of Linear Difference Models Under Rational Expectations", Econometrica, Vol. 48, N 5 (July, 1980).

[16] Den Haan W. J. and De Wind J. (2012), "Nonlinear and stable perturbation-based approximations", Journal of Economic Dynamics and Control, 36 (10), 1477-1497.

[17] Kim J. and Ruge-Murcia F. J. (2011), "Monetary policy when wages are downwardly rigid: Friedman meets Tobin", Journal of Economic Dynamics and Control, 35 (12), 2064-2077.

[18] Holden T. and Paetz M. (2012), "Efficient Simulation of DSGE Models with Inequality Constraints", Quantitative Macroeconomics Working Papers 21207b, Hamburg University, Department of Economics.

[19] Lindé J., Smets F., and Wouters R. (2016), "Challenges for Central Banks' Macro Models”, Working Paper Series 323, Sveriges Riksbank (Central Bank of Sweden).

[20] Bianchi F. and Melosi L. (2014), "Escaping the Great Recession”. NBER Working Papers 20238, National Bureau of Economic Research, Inc.

[21] Chen H. (2014), "Assessing the effects of the zero-interestrate policy through the lens of a regime-switching dsge model". Finance and Economics Discussion Series 2014-38, Board of Governors of the Federal Reserve System (U.S.).

[22] Binning, A. and Maih, J. (2016), "Implementing the Zero Lower Bound in an Estimated Regime Switching DSGE model". Working Paper 2016/3, Norges Bank.

[23] Benigno G., Foerester A., Otrok C., Rebucci A., and Young E. R. (2017), "Estimating macroeconomic models of financial crisis: An Endogenous Regime Switching Approach". 2017 Meetings Papers 572 Society for Economic Dynamics.

[24] Smets F. et Wouters R. (2003), "An Estimated Dynamic Stochastic General Equilibrium Model of the Euro Area", Journal of the European Economic Association, September 20031 (5): 1123-1175.

[25] Tinel, B. (2016), "Le fonctionnement des comptes d'opérations et leur rôle dans les relations entre la France et les pays africains", Document de Travail du Centre d'Economie de la Sorbonne.

[26] Guillaumont, S. J. et P. Guillaumont (2017), “Quel avenir pour les francs CFA?" Document de Travail du FERDI.

[27] Nubukpo, K. (2007), Politique monétaire et servitude volontaire: la gestion du franc CFA par la Banque Centrale des Etats de l'Afrique de l'Ouest (BCEAO) ", Politique Africaine $\mathrm{n}^{\circ} 105$, mars 2007, Karthala, Paris, pp. 70-82.

[28] Diop, I. T., F. Gueye et A. A. Mbaye (2017), "Sortie des pays africains de la zone Franc: entre le mythe et la réalité, Transformations", Revue Interventions économiques, Mars 2017.

[29] Gomba E. B., Kenkouo G. A., Mvondo E. T., Nafe Daba (2017), "Chocs et fluctuations macroéconomiques au Cameroun", BEAC Working Paper.

[30] Mvondo T. (2019), "Réformes financières et formation des taux d'intérêt en Afrique Centrale: une approche à travers le modèle DSGE", Revue Interventions économiques, $N^{\circ} 61$. 
[31] De Zamaroczy M., Fleuriet et V., J. Gijon (2018), “Gestion des réserves internationales de la CEMAC: une nouvelle approche à moyen terme", Fonds Monétaire International.

[32] Mundell R. (1961), "A Theory of Optimum Currency Areas", American Economic Review, 51, 1961.

[33] Mc Kinnon R. I. (1963), "Optimum Currency areas", American Economic Review.

[34] Kenen P. B. (1969), "The Theory of Optimum Currency Areas: An eclectic View in R. A. Mundell and Swoboda, A. K.," (eds) Monetary Problems of the International Economy, pp 41-60 University of Chicago Press.

[35] Elhiraika A. et Ndikumana L. (2009), "L'Accumulation de réserves dans les pays africains: sources, motivations et effets", Actes de la Conférence économique africaine, Addis Abeba (Ethiopie) du 15 au 17 novembre 2007.

[36] Mohanty M. and Turner P. (2006), "Foreign exchange reserve accumulation in emerging markets: what are the domestic implications?" BIS Quarterly Review.

[37] Calvo G. A. (1983), "Staggered Prices in a UtilityMaximizing Framework", Journal of Monetary Economics 12: 383-98.
[38] Dixit A. K and Stiglitz J. E. (1977), "Monopolistic Competition and Optimum Product Diversity", American Economic Review, Vol. 67 №3 (June 1977), pp. 297-308.

[39] Mvondo T. (2011), "L'hypothèse de neutralité monétaire: une application en Zone Franc", Thèse pour le Doctorat en Sciences économiques, Université de Nancy 2.

[40] Ngomba Bodi F. G. et Onomo Betsama J. (2018), “Analyse du multiplicateur monétaire en Zone CEMAC: Evolution, stabilité et prévision", BEAC Working Paper.

[41] Mvondo E. T. (2016), "Formation des habitudes et consommation agrégée dans la CEMAC", BEAC Working Paper.

[42] Berg A., Portillo R., Yang S. and Zanna L. (2012), "Public Investment in Resource-Abundant Developing Countries", IMF Working Paper.

[43] Bikaï J. L., et Mbohou Mama M. (2016), "Une fonction de réaction pour la Banque des Etats de l'Afrique Centrale dans un contexte de dominance budgétaire", BEAC Working Paper.

[44] Mounkala E. U., Keungne L. S. and Munkam M. A. (2016), "Optimalité de la politique monétaire de la BEAC depuis 2001”, BEAC Working Paper. 